\title{
PISADA DE LA UVA Y LAGAR TRADICIONAL EN CHILE Y ARGENTINA (1550-1850) ${ }^{1}$
}

\author{
GRAPE CRUSHING AND TRADITIONAL WINE PRESSES \\ IN CHILE AND ARGENTINA (1550-1850)
}

\section{PABLO LACOSTE², MARCELA ARANDA33, JORGE MATAMALA \\ ESTELA PREMAT, KATHERINE QUINTEROS ${ }^{6}$, NATALIA SOTO ${ }^{7}$ JOCELYN GAETE ${ }^{8}$, JAVIER RIVAS ${ }^{9}$, MARIO SOLAR ${ }^{10}$}

\section{RESUMEN}

El lagar es el recipiente donde se pisa la uva y comienza el proceso de elaboración del vino. Es relevante tanto por su significado industrial y económico como por sus implicancias sociales y culturales. El artículo contribuye al conocimiento de la historia socioeconómica de la región estudiada y, a la vez, puede ser una contribución al desarrollo de la puesta en valor de métodos tradicionales de la industria del vino que ahora se están usando de nuevo, tanto para elaborar vinos Premium como para el turismo del vino.

Palabras clave: Lagar, pisada de uva, industria vitivinícola, historia económica, enoturismo.

${ }^{1}$ Proyecto Fondecyt 1080210.

${ }^{2}$ Doctor en Historia (Universidad de Buenos Aires), Doctor en Estudios Americanos (Universidad de Santiago de Chile, USACH), y profesor titular del Instituto de Estudios Avanzados Universidad de Santiago de Chile. Santiago, Chile. E-mail: pablo.lacoste@usach.cl

${ }^{3}$ Doctora en Historia (Universidad Nacional de Cuyo), posdoctoranda (USACH) y profesora adjunta de la Universidad Nacional de Cuyo. Mendoza, Argentina.

${ }^{4}$ Profesor de Música (Universidad Metropolitana de Ciencias de la Educación) y alumno del doctorado en Estudios Americanos (USACH). Miembro fundador del grupo de música y teatro medieval "Calenda Maia”.

${ }^{5}$ Arquitecta (Universidad de Mendoza), Licenciada en Historia del Arte, Magíster en Arte Latinoamericano y doctoranda en Historia Universidad Nacional de Cuyo. Mendoza, Argentina.

${ }^{6}$ Licenciada en Historia (Universidad Andrés Bello) y alumna del Magíster en Historia (Pontificia Universidad Católica. Santiago, Chile).

${ }^{7,8,9}$ Estudiantes de la carrera de Historia de la Universidad de Santiago de Chile.

${ }^{10}$ Licenciado en Historia (Universidad Nacional de San Juan, Argentina). 


\section{ABSTRACT}

The wine press is a vessel where grapes are crushed and where the process of the elaboration of wine begins. It is relevant not only for its industrial and economic significance but also for its social and cultural implications. This article contributes to the understanding of the socioeconomic history of the region under study while at the same time serving as a contribution to the development of the recognition of the value of the traditional methods of the wine industry that once again are being used for the elaboration of Premium wines as well as for wine tourism.

Keywords: Wine press, grape crushing, wine industry, economic history, enotourism.

Recibido: 19.09.10. Aceptado: 23.02.11.

$\mathrm{E}$ L LAGAR es el recipiente en el cual se coloca la uva después de la vendimia para pisarla y producir el jugo de uva o mosto. Es la primera actividad del proceso de elaboración del vino, o sea, el lagar es el punto de contacto entre la viña y la bodega, entre la uva y el vino, entre lo agrícola y lo industrial. El lagar bien puede representar el primer espacio de transformación cultural del fruto en producto elaborado por el hombre (Maby: 2004). Se realiza allí una especie de rito de pasaje de lo natural a lo humano que sumará, entre sus diversos componentes biológicos, arquitectónicos y simbólicos, la celebración y la fiesta como parte de la cultura del vino.

El lagar y la pisada de la uva forman parte importante del paisaje cultural del mundo del vino y de la creación artística de los pueblos viticultores. En la civilización egipcia y en la antigüedad romana se realizaron representaciones iconográficas de lagares y pisadas de uva (Ruiz Mata, 1995: 168; Salcedo Garcés, 1996; Cerrillo Martín, 1996; Unwin, 2001: 199; Miret, 2005). La pisada de la uva ha construido una larga tradición como escenario de convergencia entre lo económico y lo social; lo individual y lo colectivo (amor, amistad); lo laboral y lo lúdico; la nutrición del cuerpo (alimento) y del alma (arte).

Los pueblos viticultores descubrieron que la dura tarea de pisar la uva en el lagar se realizaba con mayor eficacia si se llevaba a cabo con determinados ritmos. Se incorporó entonces la música y el trabajo se convirtió en danza. El lagar se fue erigiendo, entonces, en una suerte de vórtice, que permitía pasar del sacrificado mundo laboral al alegre espacio de la fiesta. Y se hizo cada vez más difícil separar uno del otro. Faltan estudios sistemáticos sobre el tema, pero se sabe que en España se pisaba la uva al ritmo de música africana (Artola Beuzón, 2005: 68). El lazo de la pisada de la uva y 


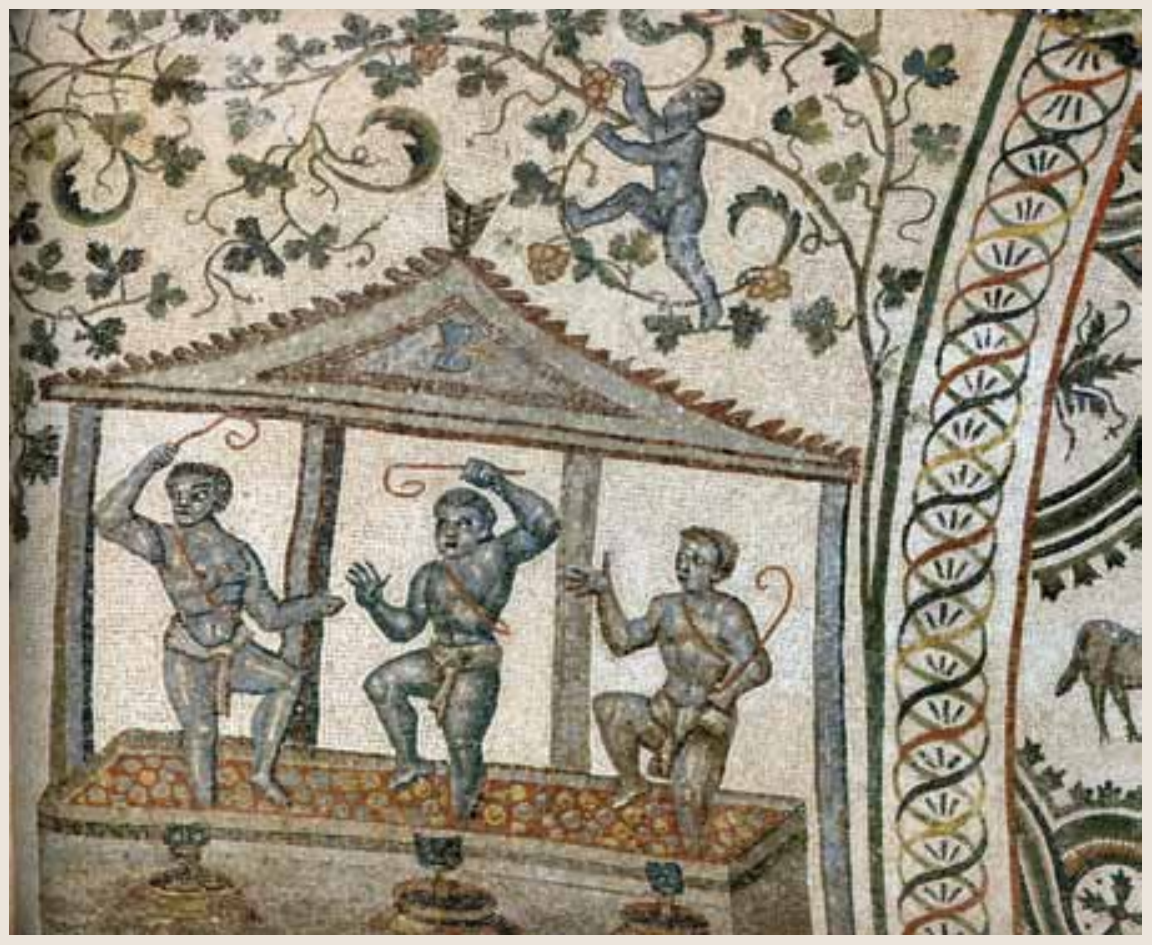

Figura 1. Pisada de la uva en la cultura romana. Mosaico del techo de la iglesia de Santa María, Roma.

la música se ha revivido, recientemente, en Jorge Drexler cuyos versos destacan el valor simbólico de la pisada de la uva por su capacidad de activar la vida social y el amor ${ }^{11}$.

La uva se ha pisado tradicionalmente con pie de hombre, desde los orígenes de la historia del vino, en las antiguas culturas de Egipto, Cartago y Grecia, hasta las transformaciones industriales de fines del siglo XIX. Durante miles de años se fortaleció el significado del lagar como espacio vinculado a la vida, la alegría y el encuentro. De esta forma, el lagar y la pisada de la uva fueron modelando los sistemas simbólicos de los pueblos viticultores. En la última centuria se dejó de pisar la uva a pie, para molerla

${ }^{11}$ En "Todo se transforma” el cantautor uruguayo evoca un lagar de La Rioja, "donde se pisaba el vino que cayó en tu boca roja; tu boca roja en la mía; la copa que gira en mi mano; y mientras el vino caía, supe que (...) el amor que me darías, transformado volvería, un día, a darte las gracias". 
con medios mecánicos. Sin embargo, en los últimos años se observa una recuperación de los métodos tradicionales.

La pisada de la uva a pie en lagar artesanal está resurgiendo. Se percibe un proceso de recuperación de estas prácticas debido, precisamente, a la fascinación que producen en el público. El primer paso lo dio el arte, particularmente el cine. Basta recordar las primeras imágenes de la película El fierecillo domado (Il bisbetico domato), dirigida por Franco Castellano y Pipolo y protagonizada por Adriano Celentano y Ornella Muti (1980) ${ }^{12}$. La pisada de la uva en el lagar es también escena decisiva en Un paseo en las nubes ( $A$ walk in the clouds), pues marca el inicio de la historia de amor entre los personajes de Keanu Reeves y Aitana Sánchez-Gijón, bajo la inquietante mirada de Anthony Queen (1994) ${ }^{13}$. Esta pisada se realiza en un entorno musical de fuertes significados simbólicos. Se entona una canción en lengua nahuatl; se toca el teccitztli ("gran caracola que servía como trompeta" (Siméon, 2004: 443)) a los cuatro vientos, con lo cual recrea una tradición indígena mesoamericana de invocación a los dioses del viento. En la antigüedad se solía tocar la caracola al inicio de los rituales de sacrificios humanos, que tenían como fin alimentar al sol con la sangre de los grandes guerreros para que la vida continuara. Nos encontramos, una vez más, con el binomio sangre-vida, que en el mundo occidental tanto se representa con el vino. Esta escena marca, pues, un mestizaje cultural puro, sincretizado en la pisada de la uva. En determinado momento se invita a la protagonista a ingresar al lagar porque "ahora es una mujer casada", en alusión evidente a la fertilidad que deja de ser potencia para convertirse en acto. Vida y fertilidad se aúnan en el lagar. Los directores y productores de ambas películas no hicieron nada más que retomar un tema tradicional: pusieron en foco la pisada de la uva como espacio social, como lugar de convergencia y de encuentro, de creación y de vida.

La mirada artística puso en foco el potencial de belleza que podía ofrecer la pisada de la uva. Y, poco a poco, se comenzaron a recrear estas prácticas en vivo. La pisada de la uva resurge en fiestas vendimiales y como atracción turística, en el marco de un proceso que se extiende de Europa

\footnotetext{
${ }^{12}$ En esta escena se produce una competencia entre la pisada de uva a pie de hombre y molida por una máquina, con ventaja para la primera opción; la ceremonia se realiza en un contexto de fiesta, baile, música y alegría. http://www.youtube.com/watch?v=MG_nWexKE8A\&feature=player_ embedded\#

${ }^{13}$ En esta película, la pisada de la uva es una escena bella y sensual, a la vez que alegre y pintoresca. Con estos cuatro elementos, esta escena ha captado algo de la esencia de la cultura del vino. Y puede figurar entre las más hermosas escenas de la historia del cine: http://www.youtube.com/ watch?v=N5yqjFUhFmg [Consultado 19 de agosto de 2009].
} 
a América. En España, la pisada de la uva puede verse del principado de Asturias a Andalucía, y de Castilla a Valencia. Algunas fiestas se caracterizan por su carácter solemne y la fuerte presencia de las instituciones más tradicionales, como en Logroño ${ }^{14}$. Otras se caracterizan por la innovación, como se percibe en el "pisado de la uva nocturno" que organiza la Denominación de Origen Cariñena (Aragón). En México, la pisada de la uva ya es parte central de las fiestas vendimiales y las propuestas enoturísticas, tanto en Baja California como en Parras (Coahuila). En Perú, la pisada de uva se realiza en el centro y sur del país (de Lima a Ica), en un entorno de música y danza. En Chile, la pisada es más rudimentaria, pero se celebra con entusiasmo en distintas localidades, desde los alrededores de Santiago (Buin, isla de Maipo) hasta las profundidades del Valle Central (Santa Cruz, Marchigüe y Molina $)^{15}$. En Argentina la pisada de la uva tiene una trayectoria relevante en Mendoza, en el marco de la Fiesta Nacional de la Vendimia. Pero últimamente se ha comenzado a realizar también en otras provincias como Córdoba (Colonia Caroya) y La Rioja (Anjullón). Además de las fiestas vendimiales, algunas viñas han comenzado a realizar este ritual como parte de su propuesta enoturística. Las viñas de Heretat de Cecilia (Alicante, España) y Viniterra (Mendoza, Argentina) son buenos ejemplos. El turista valora la posibilidad de experimentar la sensación de pisar la uva con sus propios pies.

De acuerdo a las conclusiones del I Congreso Internacional de Turismo del Vino (2007), el principal objetivo del enoturismo es activar los sentidos y las emociones del visitante: la visita a una viña tiene que convertirse en un acontecimiento especial. Y después de muchas pruebas de ensayo y error, las viñas han comenzado a comprender que la pisada de la uva es uno de los mejores caminos para alcanzar esa meta: son múltiples las sensaciones que esa experiencia ofrece al turista, pues se trata de vivencias que se co-

\footnotetext{
${ }^{14}$ El pisado de la uva en Logroño es una fiesta formal, cívico-religiosa, con participación de escolares, autoridades de gobierno y representantes de todas las localidades vitivinícolas de La Rioja. Incluye procesiones de imágenes sacras y desfile de vecinos con trajes típicos. Niños de distintos colegios hacen la ofrenda de los racimos de uva para cargar el lagar de madera o tinanco. Culmina con la pisada de la uva, a cargo de dos adultos varones http://www.youtube.com/ watch?v=XwXFEugS-BM. http://www.youtube.com/watch?v=8-3poWp-QVc\&NR=1 [Consultado 18 de agosto de 2009].

${ }^{15}$ La pisada de la uva en Ica (sur del Perú) se realiza en un lagar de material permanente, de grandes dimensiones. Participan mujeres y varones, jóvenes y mayores en un clima de fiesta popular, danza y música. Los instrumentos musicales utilizados son cajón peruano, cencerro y bongó. http://www.youtube.com/watch?v=-mBDONRSb_4\&feature=related [Consultado 18 de agosto 2009]. En las fiestas vendimiales de Molina, Buin e Isla de Maipo (Chile), la pisada de la uva es realizada por jóvenes varones, en pequeños lagares de madera: http://www.youtube.com/ watch?v=ZBro_ePgtg8\&feature=related [Consultado 18 de agosto de 2009].
}

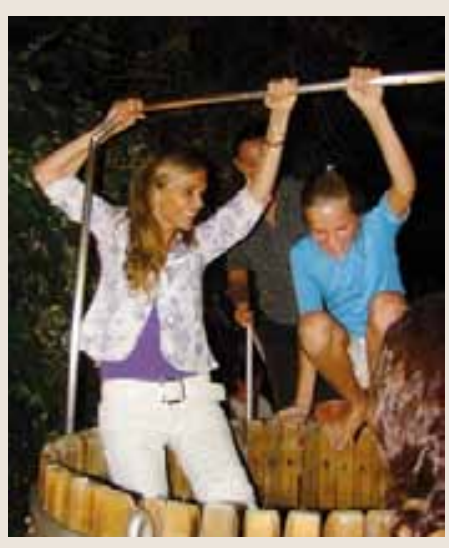

Figura 2. Turistas pisan la uva en lagar de madera en Viñas Viniterra (Mendoza, 2009). 
nectan con prácticas ancestrales, profundamente arraigadas en sus niveles inconscientes ${ }^{16}$.

La pisada de la uva desencadena una serie de acciones plenas de sentido: abandonarse a una experiencia dionisíaca; sentir la textura de la uva debajo de los pies; estrujar las bayas y ponderar su relativa resistencia; percibir la sensación líquida del mosto entre los dedos, y el perfume que se comienza a liberar, todo ello en un contexto de música, luces y celebración. Se activan los sentidos del tacto, el olfato y el oído; el gusto y la vista. La pisada de la uva fascina.

El interés por la tradicional pisada de la uva va más allá de la observación. Algunas viñas han comenzado a recuperar estas costumbres para elaborar vinos Premium. En los últimos años, bodegas como Faelo (Alicante), Celler de la Muntanya (Valencia), y J.W. Burmester (Portugal-UK) han lanzado vinos elaborados con uva pisada a pie, a la usanza tradicional. En América del Sur se puede citar el caso de "El Cabernet de las Reinas", elaborado por bodega Orfila (Mendoza) a partir de la uva pisada por las reinas de la fiesta nacional de la vendimia. Las prácticas enológicas tradicionales están volviendo al mundo del vino.

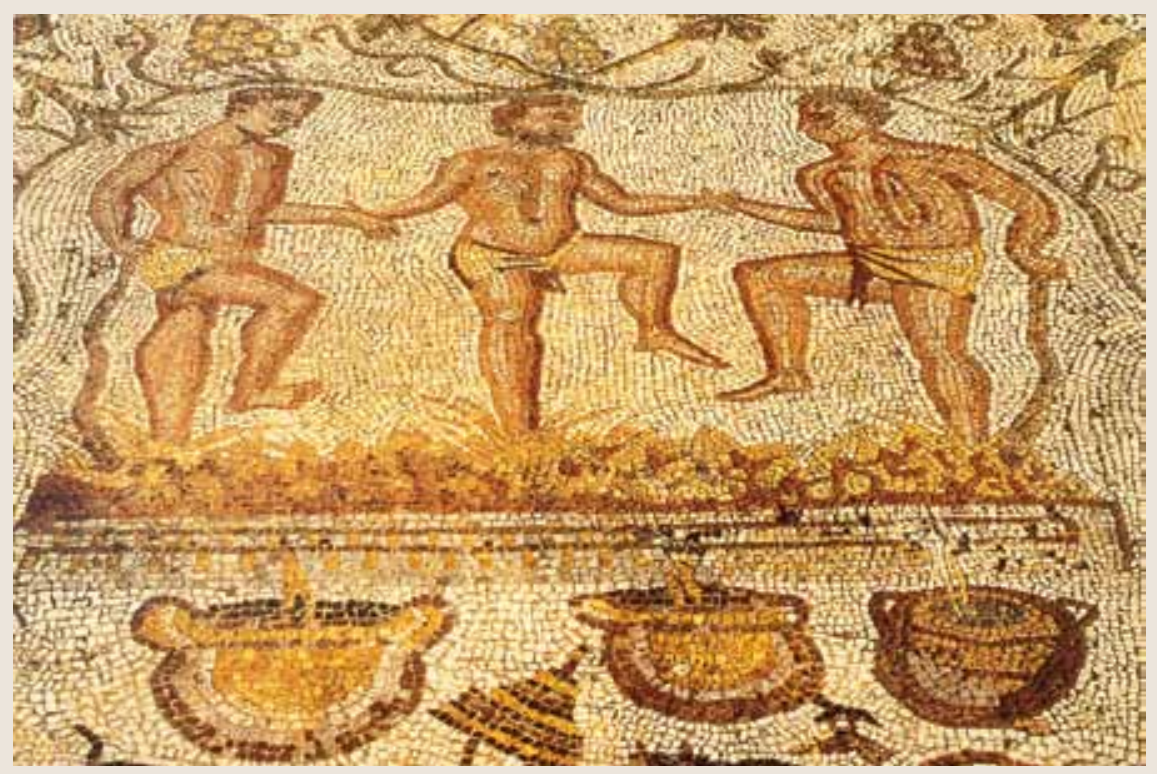

Figura 3. Representación de la pisada de la uva en el mosaico de Venus y Eros, siglo III. Mérida, Casa del Anfiteatro. Fuente: Celestino Pérez, 1996.

${ }^{16}$ Conclusiones del I Congreso Internacional de Eno Turismo. Jerez de la Frontera, Universidad de Sevilla, 3, 4 y 5 de diciembre de 2007. 
Así, entonces, el estudio de la historia de los lagares tiene un doble interés. Por un lado, contribuye a generar conocimiento aplicable a los actuales proyectos de enoturismo y de elaboración de vinos Premium, todo ello en el marco del fortalecimiento de la identidad de los vinos locales y la recuperación de métodos tradicionales que actualmente son valorados por los mercados. En segundo lugar, la investigación sobre esos lagares contribuye a comprender mejor los procesos históricos de los pueblos viticultores y sus implicancias sociales, económicas y culturales, en un contexto internacional muy específico.

En efecto, el estudio de los lagares de una región (en este caso, Chile y Argentina) exige interpretar el tema como parte de un proceso mayor que comprende la historia vitivinícola de Europa y América. Los datos vitivinícolas registrados y guardados en el Archivo Nacional de Santiago de Chile y en los archivos provinciales de Mendoza y San Juan, no se pueden interpretar sin tener presente la cultura de la vid y el vino en el mundo, particularmente en Europa, en los siglos estudiados y en la tradición construida a lo largo de la historia. Sin ese contexto, resultan incomprensibles muchas palabras técnicas que los notarios han registrado. Hay una especificidad muy particular, por tratarse de una industria compleja con sus propios códigos y tradiciones.

El estudio de los lagares, como parte de un proceso industrial, permite avanzar en el conocimiento de aspectos hasta ahora desconocidos de la historia socioeconómica de estos países. Por ejemplo, en las negociaciones entre viticultores y bodegueros, la disponibilidad del lagar afectaba la correlación de fuerzas entre las partes, dado el carácter perecedero de la uva. El nivel de accesibilidad del viticultor al lagar era un asunto de fuertes implicancias sociales y económicas. A ello hay que añadir otros elementos: el lagar planteaba una oportunidad para el fortalecimiento de la cultura de la reinversión de la renta, el desarrollo de técnicas constructivas y la articulación de la viticultura con otras actividades económicas (agricultura, ganadería, curtiduría, herrería, carpintería, construcción, transporte, comercio). Por lo tanto, el estudio de estos problemas contribuye a un mejor conocimiento de la historia social y económica del país.

El lagar es un espacio central en la vida de los pueblos vitivinícolas. Y ha mantenido su relevancia durante miles de años. Los lagares romanos excavados en piedra se han usado a lo largo del medioevo y hasta los albores de la modernidad. Asimismo, en muchos pueblos viticultores de la antigüedad, los principales rastros que han dejado de su cultura son, justamente, sepulcros y lagares de piedra (Ferreira, Brochado y Rodríguez, 2000). En 


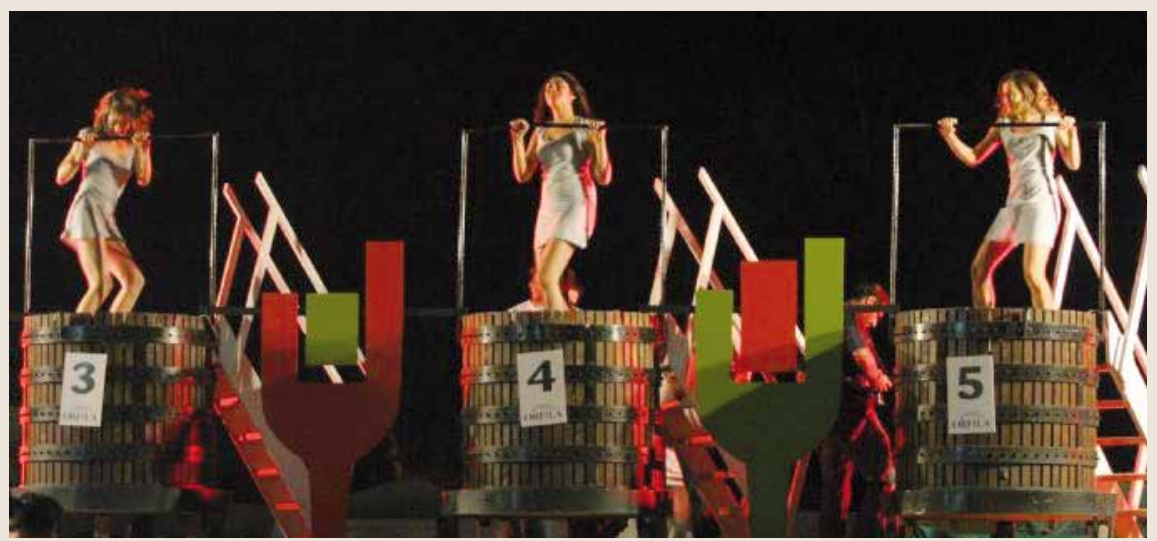

Figura 4. Celebración de la pisada de la uva, en el marco de la Fiesta Nacional de la Vendimia (Mendoza, febrero 2008). Fuente: Diario Los Andes. Con el mosto producido en esta pisada se elabora el "Cabernet de las Reinas".

ese sentido, el lagar ha sido más trascendente que las demás instalaciones y equipamiento de la producción vitivinícola, superando a la viña, la bodega y la vasija. El lagar y el sepulcro. La vida y la muerte. Dos caras de una misma moneda.

La literatura especializada ha reflejado su interés por los lagares a través de numerosas publicaciones. En algunos casos, el lagar ha ocupado un lugar relevante dentro de estudios más amplios, dedicados a la vitivinicultura (Guyot, 1861; Rojas, 1891; Lesko, 1978; Meeks, 1993; Ruiz Mata, 1995; Cerrillo Martín, 1996; Salcedo Garcés, 1996; Artola Beuzón, 2005). En otros casos, el lagar ha sido el foco central de trabajos de investigación (Rodríguez Martín, 1988; Gómez y Guerin, 1995; Brochado y Costa Pinto, 1997; Ferreira, Brochado y Rodríguez, 2000; Rodríguez Cosme, 2001; Laranjeira, 2001 y 2004; Viana Antunes y Baère, 2002). Se han considerado sus diseños, dimensiones y materiales de construcción, entre otros elementos.

En el Cono Sur de América, el lagar también ha despertado el interés de los especialistas. En primer lugar, los estudios de Gay (1855) pusieron en foco la presencia, en la viticultura chilena de mediados del siglo XIX, de dos modelos principales: los lagares de cuero en las viñas pequeñas y los lagares de ladrillo en las grandes haciendas; esa fue la conclusión del autor a partir de sus observaciones en terreno (Gay, 1855: 190-191). Más recientemente, los historiadores han retomado el tema, tanto desde la arqueología histórica como desde la historia documental. En la primera rama se destacan 


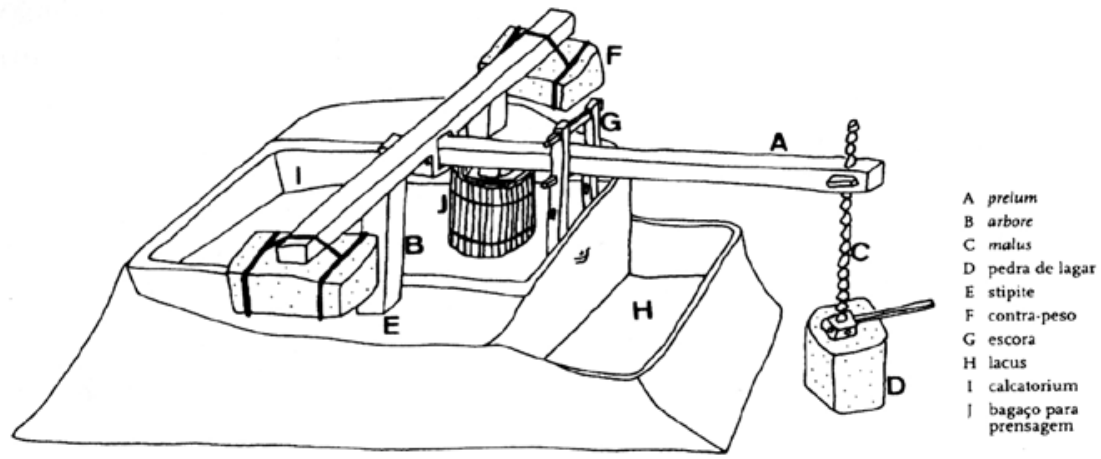

Figura 5. Lagar tradicional en Portugal. Fuente: Larangeira (2004).

los trabajos de Rice y Smith sobre la viticultura colonial peruana (1989, 1991, 1996). Estos arqueólogos pudieron realizar observaciones directas de los lagares sepultados por las erupciones volcánicas de fines del siglo XVII, con lo cual generaron valiosa información para el actual proyecto. Paralelamente, los historiadores examinaron el tema a partir de los documentos escritos generados por cronistas y notarios de la época anterior a Gay. Una decena de lagares de la jurisdicción de Colchagua en el siglo XVII fueron detectados por Muñoz (2001). Otros 27 lagares de las haciendas jesuitas de Concepción fueron descriptos por Sánchez Andaur (2006) para el siglo XVIII. En esa misma centuria, pero en San Juan, López (2005) y sobre todo Rivera (2007a y b) detectaron dos decenas más de lagares. A ello se suman las descripciones de cronistas reunidas por Del Pozo (1999). En total, la literatura especializada ha reunido datos de varias decenas de lagares. Paralelamente, en el trabajo de archivo realizado en la presente investigación se han detectado casi seis centenares más. En total, se ha podido disponer de un corpus documental con datos precisos de 682 lagares correspondientes a las principales regiones productivas de las actuales repúblicas de Argentina y Chile, desde mediados del siglo XVI hasta mediados del XIX, incluyendo San Juan, Mendoza, La Serena, Santiago, San Felipe, San Fernando, Parral, Talca, Cauquenes y Concepción. Se ha cubierto una superficie de 1.000 kilómetros de norte a sur, por 400 kilómetros de este a oeste. Las fuentes son los inventarios de bienes registrados con motivos de testamentos, codicilos, tasaciones testamentarias y otros expedientes judiciales, juntamente con las temporalidades de los jesuitas. 


\section{ALGUNAS PRECISIONES CONCEPTUALES}

El lagar era parte de un conjunto de instalaciones y equipamiento de la bodega. El lagar iba acompañado por lagareta, piquera, pilón y husillo. En la España del siglo XVII se denominaba lagar a "la balsa donde estrujan la uva y la pisan, latine lacus, de donde tomó nombre. También se dice lacuna torcular porque tuercen el husillo de la viga, y cuando ha salido el buen mosto, lo que exprimen después echándole algún poco de agua, llaman torceduras" (Covarrubias, 1995 [1611]: 697). Para los españoles del siglo XVIII, el lagar era "especie de estanque pequeño o alberca donde pisan la uva. Tiene un canillero para que salga el mosto, el cual es recibido en una tina u otra vasija, para conducirlo a las cubas o tinajas" (RAE, 2002 [1726, II]: 350). Por su parte, la lagareta era "lagar pequeño".

En la cultura romana el lagar tenía tres partes: el sitio de pisada de la uva (calcatorium), de base generalmente cuadrada o rectangular; el receptáculo para el mosto (lacus), de planta con frecuencia circular; y el ducto que enlazaba los dos anteriores. En la región estudiada, el calcatorium romano era llamado "lagar"; el lacus se denominaba "pilón" y el ducto conector era la "piquera". Es oportuno señalar también que, por lo general, existía cierta armonía en los materiales utilizados para todos estos objetos. Los lagares de cuero se usaban con pilones de cuero, llamados noques. En algunos casos se usaban pilones de tinaja, es decir, de barro cocido o cerámica. Los lagares de piedra o de ladrillo usaban pilones del mismo material. En la sofisticada hacienda jesuita de Calera de Tango (cerca de Santiago de Chile), los lagares tenían "tres piqueras crecidas con calicanto, con su fondo de greda" ${ }^{17}$.

Más allá de la acción específica de pisar la uva, el lagar emergió como un símbolo de la industria de la vid y el vino. Este espesor cultural del lagar ha proyectado su nombre para representar un fenómeno muy amplio y complejo. La definición de Jules Guyot es ilustrativa:

"Le mot vendangeoir exprime l'ensemble des vignes et des bâtiments qui servent à leur exploitation; il est appliqué également à un pied-àterre, à une maison ou même à un château dont un vignoble est la principale dépendence. Le vendangeoir est à la vigne ce que la ferme et aux terres arables. On a un vendangeoir en Médoc, en Bourgogne, en Champagne, en Touraine, comme on a une ferme en Brie, en Normandie, etc. On appelle plus généralement vendangeoir les bâtiments specialement consacrés à l'explotation de la vendange" (Guyot, 1861:215).

\footnotetext{
${ }^{17}$ Inventario de bienes de la hacienda de Calera de Tango, 1767. Archivo Nacional de Santiago de Chile (en adelante AN), Fondo Jesuitas de Chile (FJCH), Volumen 2, Pieza 3, Folio 69.
} 
La palabra vendangeoir en francés se traduce al español como lagar. El concepto lagar, en español, no es tan amplio como el vendangeoir de Guyot. Por lo general, el concepto de lagar se usa para denominar el recipiente en el cual se coloca la uva después de la vendimia, para pisarla y producir el jugo de uva o mosto. El sentido que para los franceses tenía vendangeoir, equivalía al de "bodega" para los españoles. En el siglo XVII, bodega era "cueva donde se encierra cantidad de vino" (Covarrubias, 1995 [1611]: 195). Desde allí, el concepto evolucionó hacia significados más amplios. Un siglo más tarde, bodega significaba "lugar o sitio donde están las cubas o tinajas en que se encierra y guarda la cosecha de vino". También significaba "la cosecha o la abundancia de algún lugar que coge mucho vino" (RAE, 2002 [1726, I]: 634). Una centuria después, estos conceptos se mantenían casi intactos (RAE, 1852: 102). Cuando Blasco Ibáñez tomó la decisión de describir el espacio vitivinícola español, incluyendo aspectos económicos, sociales y culturales, escribió su novela titulada La bodega (1905). Dentro del Cono Sur de América, en Argentina también se usa la palabra bodega en ese sentido, mientras que en Chile bodega es una construcción en la cual se guardan cosas, y para expresar ese concepto se usa la palabra "viña".

El concepto de lagar en lengua inglesa no ha tenido un desarrollo endógeno porque el Reino Unido, por sus climas, no logró desarrollar una viticultura propia. Por lo tanto, los conceptos se incorporaron a partir de la traducción de palabras de lenguas desarrolladas en regiones vitivinícolas. $\mathrm{Al}$ no disponer de palabras propias para traducir el complejo sentido de la palabra lagar, se han usado perífrasis. En sentido amplio, lagar se traduce "pressing house, vinification plant", y se define "building or plant where the operations of crushing and pressing are done". En sentido más estricto, lagar se traduce también como "wine press, wooden trough, square trough", y se define "large, square, wooden recipient with a hole in one side as outlet for the must. Used for the treading of grapes" (Noya Gallardo, 1993: 244245).

Con respecto a las medidas, en el presente texto se emplean la arroba y la vara, tal como se usaba en las fuentes. La arroba (@) era la unidad de capacidad para medir líquidos; una arroba equivalía aproximadamente a 36 litros. La vara es una medida de longitud, equivalente a tres pies o bien, 83 centímetros. Los lagares y pilones se medían, precisamente, con estas unidades. 


\section{LAGARES DE MATERIAL PERMANENTE}

En la viticultura tradicional de Argentina y Chile se usaron lagares de dos modalidades principales: materiales perecibles y materiales permanentes. En la presente investigación se identificaron 682 lagares, incluyendo 537 de material perecible y 147 de material permanente. Los lagares de material permanente eran de adobe, ladrillos o piedra. Los de material transitorio eran de madera, cuero o cestones.

La tradición de construir lagares con materiales permanentes se remonta a la cultura egipcia y al imperio cartaginés. Las representaciones iconográficas dan cuenta de lagares bien construidos en Egipto antiguo, como ya se ha referido. Esas obras artísticas demuestran que los egipcios construyeron y usaron lagares para pisar la uva, pero nada dicen sobre los materiales empleados para su construcción. En torno a este problema existen distintas posiciones, conforme a las cuales los egipcios usaron lagares de piedra, de madera o de arcilla y yeso (Lesko, 1978: 17). Algunos lagares de piedra fueron efectivamente hallados (Meeks, 1993: 17). Pero las investigaciones conducen a enfatizar el predominio de los lagares de arcilla cubierta por una capa de yeso (Gómez Bellard y Guerin, 1995: 259).

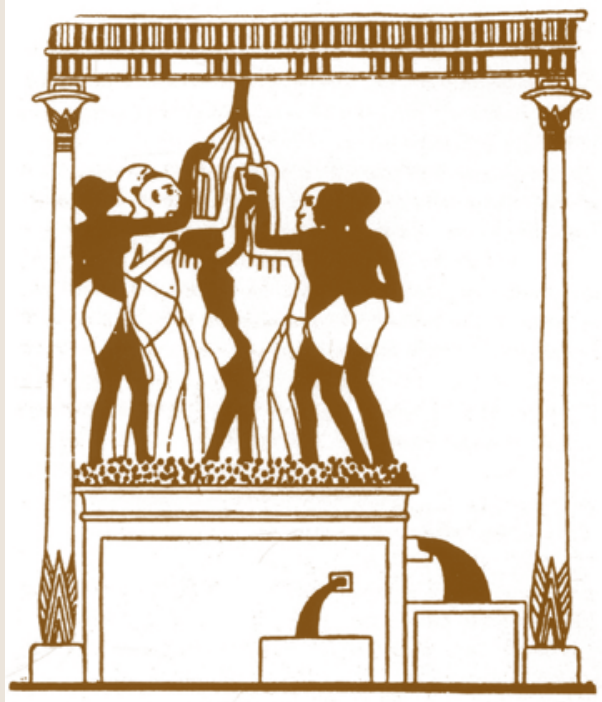

Figura 6. Pisada de la uva en Egipto según Forbes. Fuente: Celestino Pérez (1995). 


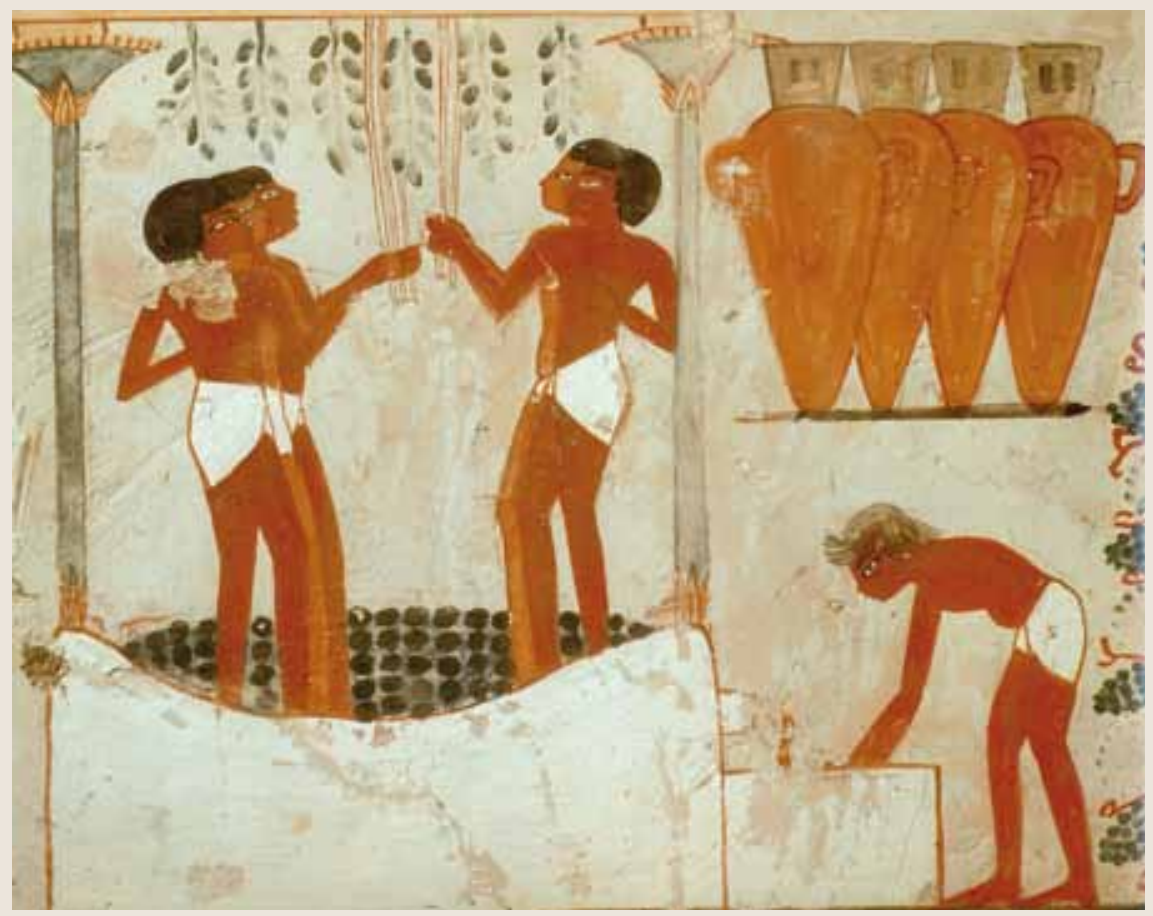

Figura 7. Pisada de la uva en Tebas, Egipto. Pintura de la tumba de Nakht, dinastía XVIII (1567-1320 a C.). Fuente: Montserrat (2005).

Los lagares también ocuparon un lugar central en la antigua Roma. Se usaron lagares de madera, lagares excavados en roca y lagares de argamasa. Estos últimos eran revestidos con un mezcla que podía ser de opus signium (llamado también opus musivum) o bien, de opus segmentatum. El primero era una mezcla de arena, cal y fragmentos de ladrillos o cerámica triturada. El segundo era igual al anterior, pero reforzado por trocitos de mármol, calizas, gres y otros materiales para proporcionar resistencia y ofrecer más riqueza cromática (Ruiz Mata, 1995: 201; Rodrigues Cosme, 2001: 57). Paralelamente, los cartagineses también afinaron sus técnicas para construcción de lagares con cal, arena, gravilla y polvo de terracota (Ruiz Mata, 1995: 198). El objetivo era disponer de un enlucido arcilloso y compacto, que facilitara la disponibilidad de una superficie lisa y limpia para realizar la pisada de la uva. Entre los siglos -VI y -III estas técnicas de estilo cartaginés y romano se difundieron hacia el mediterráneo occidental, particularmente a las costas del sur y oriente de España (Gomez Bellard y Guerin, 1995: 250; Ruiz Mata, 1995: 200-201), para expandirse después hacia el oeste y abarcar también el actual territorio de Portugal (Rodrigues Cosme, 2001). 


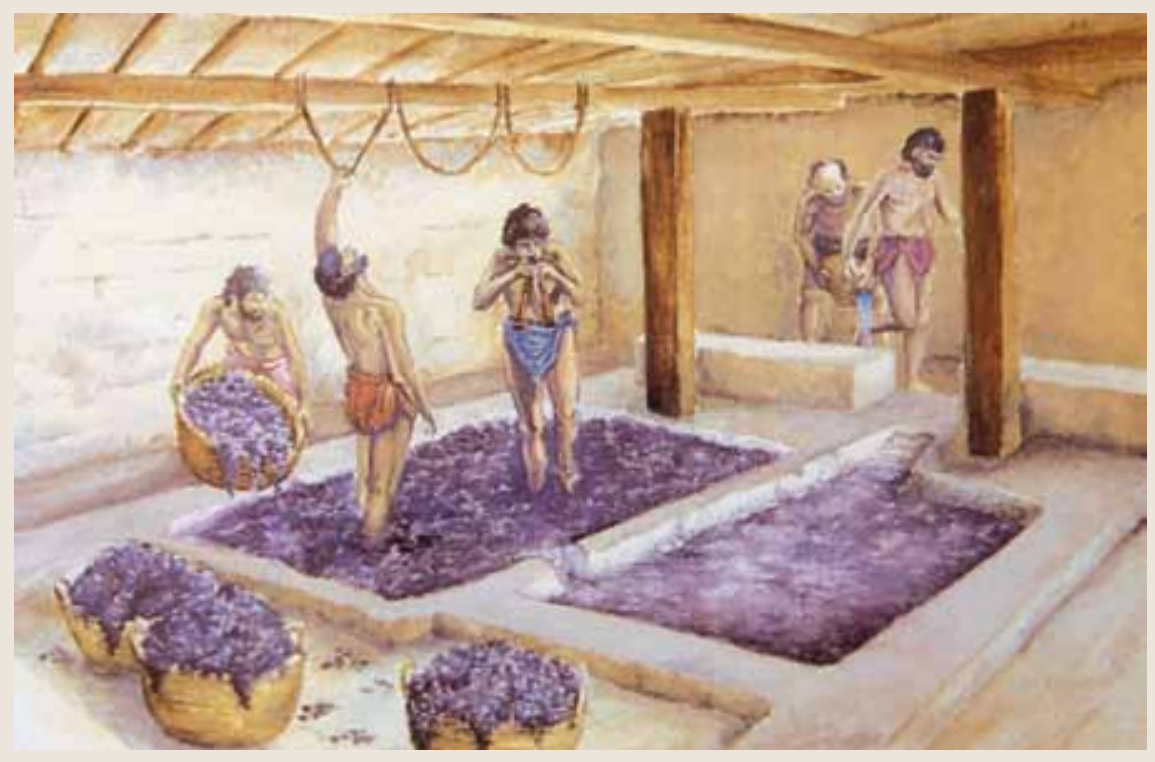

Figura 8. Pisada de la uva en lagares fenicios del sur de España. Dibujos de E. Dies y F. Chiner. En el centro, el pisador interpreta un instrumento musical de viento; posiblemente se trate de un doble aulós, construido de madera, con lengüeta ideóglota de caña. Fuente: Celestino Pérez (1995).

Es importante destacar que el lagar de piedra también logró una importante expansión. A partir de los citados antecedentes de la cultura egipcia, esta modalidad se difundió por Europa, impulsada sobre todo por la expansión romana. Hay zonas donde los lagares de piedra, construidos en la antigüedad romana, fueron usados hasta bien avanzada la Edad Media (Laranjeira, 2004).

Desde la perspectiva del presente artículo, lo importante es señalar que, al producirse el descubrimiento y la colonización de América, ya se habían consolidado en España las distintas modalidades de construcción de lagares, según los materiales disponibles en cada región. Y eso fue, justamente, lo que hicieron los españoles en el cono sur.

Los estudios de Rice y Smith abrieron el camino para el conocimiento de los lagares de material permanente en América. Usando el método propio de la arqueología, estos autores examinaron los lagares de 130 establecimientos vitivinícolas del valle de Moquegua, en el sur de Perú. Sobre esta base lograron trazar un perfil de los lagares del siglo XVII. En sus observaciones, estos autores dieron cuenta de las formas y materiales que tenían esos lagares. 
Desde el punto de vista de la forma de la planta, los lagares peruanos eran, por lo general, rectangulares o cuadrados. Seguían por lo tanto, los patrones del lagar romano. De todos modos, también se encontraron lagares redondos, aunque con menor frecuencia. En cuanto a los materiales de su construcción, los lagares estaban revestidos en su interior por bloques empotrados de piedra caliza, con forma rectangular o cuadrada (Rice y Smith, 1989: 42). Por lo general, los lagares no estaban solos: se construían en hileras de dos o tres, aunque sin normas rígidas: había también haciendas con un solo lagar, y otras podían llegar a tener nueve. En cuanto a sus capacidades, estos autores lograron medir 40 lagares y concluyeron que la capacidad media era de 12 a 14.000 litros, de lo cual se infiere que estas instalaciones -como los lagares de Roma y España- se usaban varias veces en la misma vendimia. Con respecto a los sistemas de prensado, por tratarse habitualmente de materiales perecederos, ese estudio arqueológico no logró respuestas claras (Rice, 1996: 791). Asimismo, la citada autora detectó indicios suficientes para conjeturar que esos lagares no funcionaban al aire libre, sino que estuvieron originalmente protegidos por otra construcción, generada con paredes de adobe y techada con materiales perecederos.

Más allá de los estudios arqueológicos de Rice, otros historiadores se han interesado en la viticultura tradicional peruana y sus lagares, utilizando fuentes escritas, ya de cronistas, ya de documentos originales. En líneas generales, coinciden con los enfoques de Rice: los viticultores peruanos usaban lagares de material permanente, de ladrillos o de adobe, revestidos con cal, y de formas cuadradas, rectangulares o redondas. No se mencionan lagares de cuero en los estudios de Brown (2001), Huerta (2004) y Soldi (2006).

Como se ha indicado, en el corpus documental examinado para esta investigación se encontraron 145 lagares de material permanente en las regiones estudiadas de Argentina y Chile. Dentro de este grupo, había 83 lagares de ladrillo, 40 de piedra, 14 mixtos de piedra y ladrillo y 8 de adobe.

Los lagares permanentes eran parte de la infraestructura del establecimiento vitivinícola y requerían condiciones especiales. En primer lugar, debían construirse dentro de una bodega, llamada pieza o cañón, con paredes de adobe y techos de teja o tablillas, barro y paja, según la zona. Bajo la protección de esos techos se construían los lagares.

El lagar permanente se construía con distintos materiales: los más pobres se hacían de adobe. Más higiénicos eran los lagares de ladrillo o de piedra. Esta podía ser ripio, canto rodado, piedra laja o piedra de sillería. Para unir los ladrillos o piedras se usaba cal, argamasa o mezcla. Eran los 
mejores materiales disponibles. Es importante advertir que los viticultores usaban materiales de menor calidad para sus casas (adobe) y los más valiosos para sus lagares (piedra, cal y ladrillo).
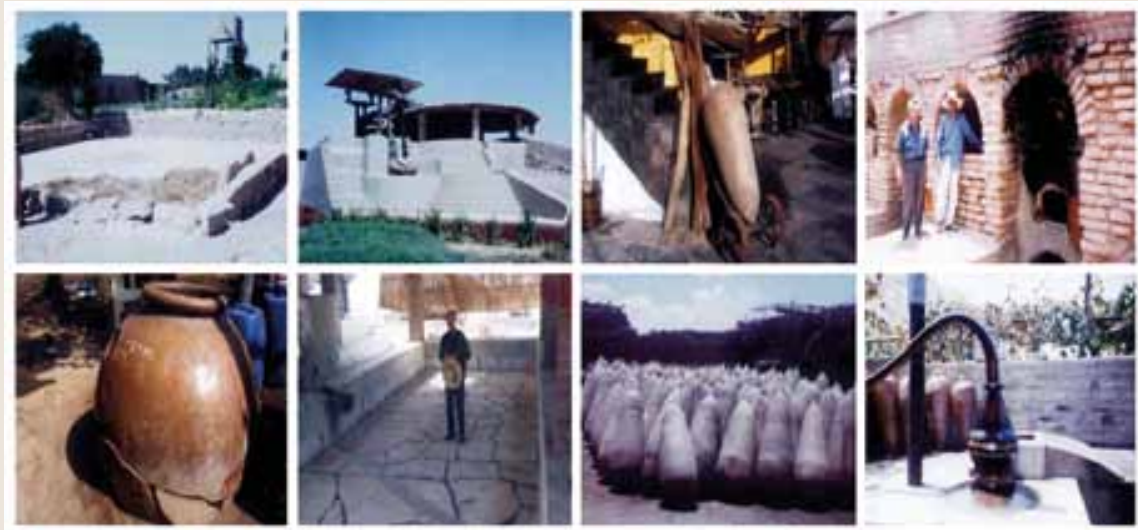

Figura 9. Instalaciones y equipamiento vitivinícola tradicional en Perú. Nótese el lagar redondo (primera fila, foto central). Fotos: Lorenzo Huerta, Bodega La Caravedo, Ica, Perú, 2006.

\section{PRENSAS, HUSILLOS, VIGAS}

Para obtener la mayor cantidad de mosto se utilizaban prensas. En el período estudiado se emplearon equipos que incluían husillos y vigas. La viga era un tablón de madera pesada, ordinariamente de olmo en el centro de España, de algarrobo en Cuyo y La Serena, y de espino en el Valle Central de Chile. Por su parte el husillo era un "cilindro cavado alrededor de muescas espirales por las cuales va bajando la tuerca y es en lo que consiste la fuerza principal de las prensas, como se ve en los lagares y en otras máquinas para apretar alguna cosa o subir algún gran peso" (RAE, 2002 [1726, II]: 195). Este tipo de equipamiento se usaba en España en general y en la rivera del Duero en particular. En un estudio sobre la industria del vino en este territorio, se describió el fenómeno en los siguientes términos:

La viga, un grueso tronco de madera de olmo, atravesaba la pila transversalmente. En uno de sus lados iba insertado un sinfín, llamado husillo, unido a un pesado bloque de piedra caliza. Al girar el husillo la 
piedra se despegaba del suelo, quedando en el aire y transmitiendo su peso a la viga, que a su vez lo hacía sobre un castillo de tablones -marranos- que, colocado encima de la masa de racimos, hollejos y rampujos, servía para estrujarlos y que hicieran fluir el mosto por los canalillos abiertos junto a las paneras (Iglesia, 2001: 349-350).

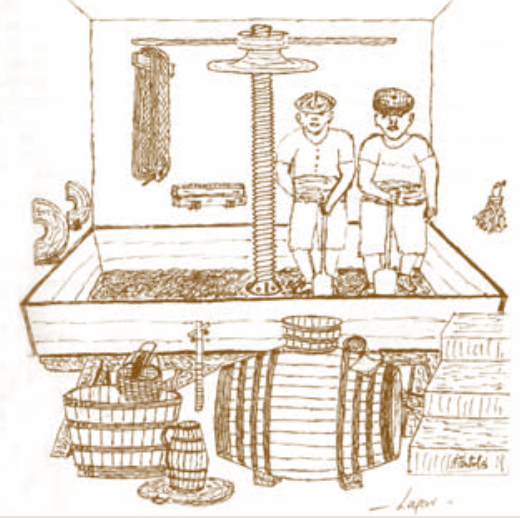

Figura 10. Pisada de la uva en lagar de madera con husillo. Fuente: Artola Beuzón (2005).

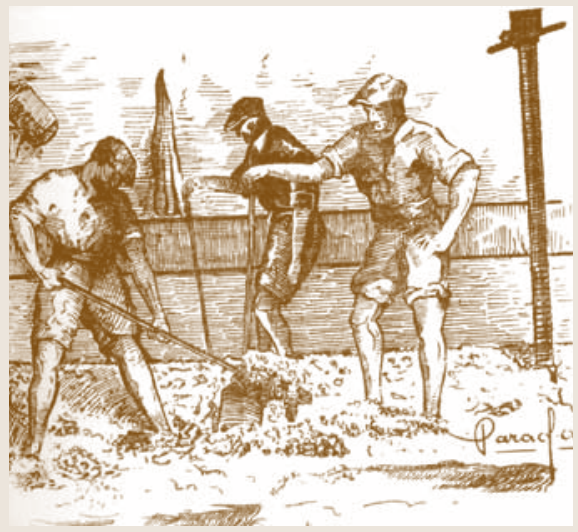

Figura 11. Pisada de la uva en lagar de madera con husillo. Fuente: González Gordon, Jerez, Xeres, Sherish, Jerez de la Frontera (1970).

Los españoles trasladaron tempranamente estas técnicas al cono sur de América. El husillo más antiguo del Reino de Chile fue registrado en La Serena, en la hacienda Rucapibi (1610). Junto a su lagar de cal y ladrillo, había "una viga grande con su husillo de algarrobo y dos piqueras"18. Don Jerónimo Pastene (La Serena, 1671) tenía "una bodega con su lagar y lagareta y vigas y prensa con su husillo de algarrobo"19. También tenían lagares con

\footnotetext{
${ }^{18}$ Inventario de la Hacienda Rucapibi, Valle de Limarí, junio de 1610. AN, FNLS, Volumen 8, Folio 186.

${ }^{19}$ Inventario de bienes de Jerónimo Pastene, Estancia Limarí, La Serena, 7 de setiembre de 1671. AN, FNLS, volumen 4, folio 428.
} 
husillo el capitán Miguel de Tordera (La Serena, 1678) y el maestre de Campo Rodríguez Rojas en la hacienda Rivadavia (también La Serena, 1678). Por su parte, el general Agustín Rojas (La Serena, 1687) tenía "lagar y tablón que sirve de prensa" ${ }^{20}$. Don Juan Moyano de Aguilar y Juana Flores (Mendoza, 1688) tenían una bodega con su lagar y su husillo, todo ello valuado en $\$ 600^{21}$. Paralelamente, en la hacienda de don Antonio Moyano Flores (Mendoza, 1699), tenía lagar y husillo, valuados cada uno en $\$ 100^{22}$. En La Serena, la hacienda Sotaqui (1702) tenía "una bodega de dos piedras en la primera dos lagares y una viga de algarrobo con su husillo, una ventana a la viña, y sus puertas clavadas con cerrojo y llave y la segunda con su puerta así mismo clavada con un candado grande"23. En esa misma jurisdicción, el capitán don Joseph de Vega (1723) alquiló una propiedad vitivinícola con "un lagar y lagareta con sus desblanderas, tres enfriaderas, y un husillo con su viga para el orujo" 24 .

Ejemplares de este tipo de equipamiento se han conservado en la Hacienda San Lorenzo, Casa Madero, en Parras, estado de Coahuila (México). Se trata de algunas prensas notables, en algunos casos, con sus correspondientes vigas y piqueras de piedra.

${ }^{20}$ Inventario de bienes del general Agustín Rojas, Valle de Elqui, 7 de enero de 1687. AN, FNLS, volumen 12, F. 226.

${ }^{21}$ Tasación de bienes de Juan Moyano de Aguilar y Juana Flores, Mendoza, 6 de octubre de 1688. AHM, Carpeta 255, Documento 2, Folio 22.

${ }^{22}$ Tasación de bienes de Antonio Moyano Flores, Mendoza, 19 de octubre de 1699. AHM, Carpeta 255, Documento 7, Folio $4 \mathrm{v}$.

${ }^{23}$ Inventario de bienes del sargento mayor Jerónimo Pizarro Caxal, La Serena, 6 de julio de 1702. AN, FNLS, Volumen 17, Folio 224.

${ }^{24}$ Carta de entrega de bienes en arriendo al capitán Joseph de Vega, estancia Limarí, jurisdicción de La Serena, veinte leguas de ella, 30 de junio de 1723. AN, FNLS, Volumen 3, Folio 633. 


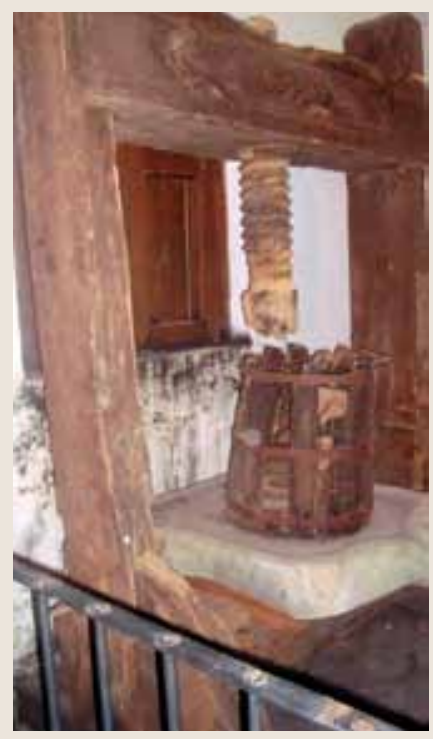

Figura 12a. Prensa con husillo, viga y piquera de piedra. Foto: PAL, Hacienda San Lorenzo, Estado de Coahuila, México, julio 2009.

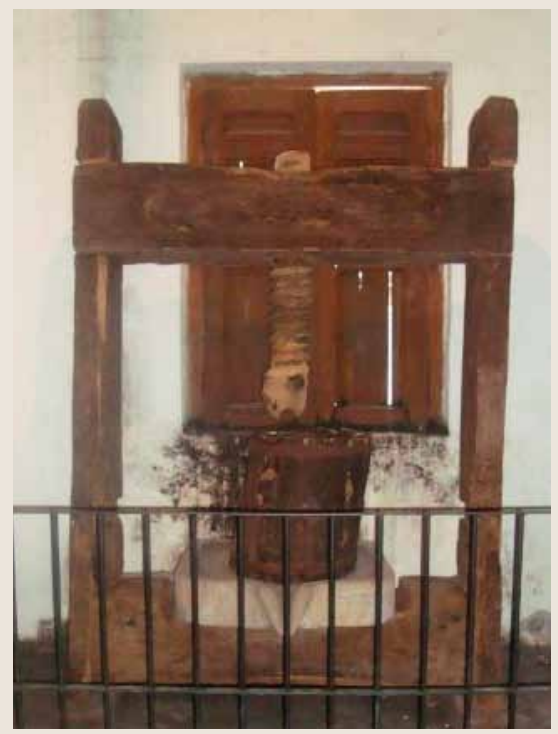

Figura 12b. La misma prensa de la foto anterior, desde otro ángulo. Foto: PAL, Hacienda San Lorenzo, Estado de Coahuila, México, julio 2009.

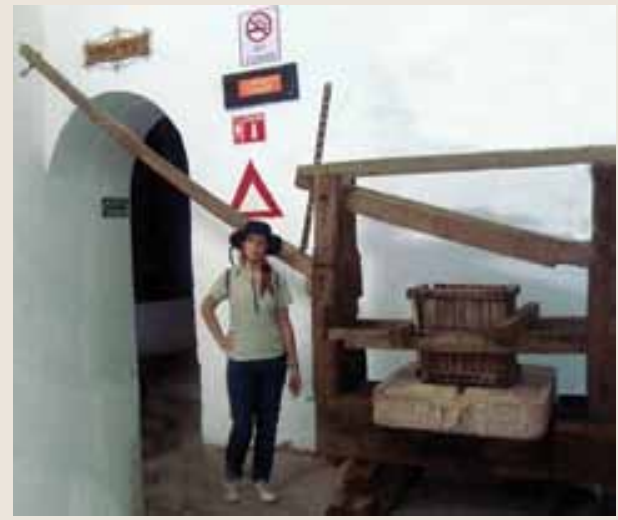

Figura 13a. Prensa con viga y piquera de piedra. Foto: PAL, Hacienda San Lorenzo, Estado de Coahuila, México, julio 2009.

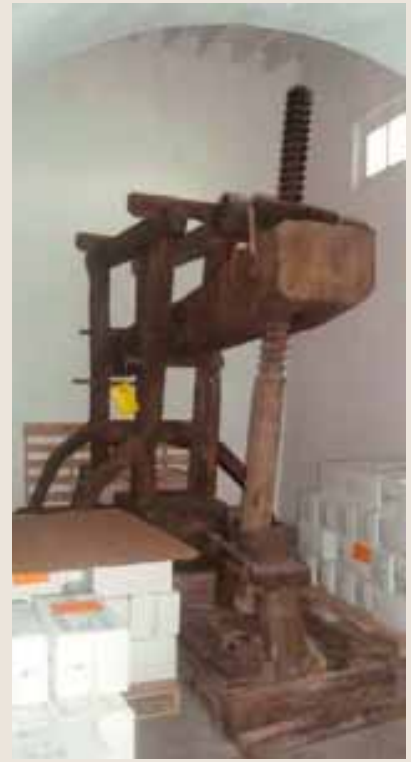

Figura 13b. Prensa con husillo y viga. Foto: PAL, Hacienda San Lorenzo, Estado de Coahuila, México, julio 2009. 
Con respecto a las prensas, un caso interesante se detectó en el sitio de Agustín del Castillo (Santiago, 1785). Junto a su viña de 37.700 cepas y sus bodegas y lagares, el viticultor tenía equipamiento para prensar el orujo. Los notarios lo describieron en los siguientes términos:

La prensa sobre solera de piedra canteada de $2 \times 13 / 4 \times 1 / 3$ varas, con canal en su contorno donde recibe el jugo de la uva con el cajón de ma-

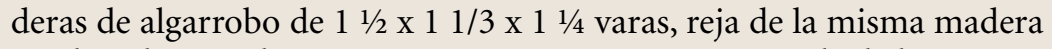
entabicada y unida con marco en su exterior, que sujeta la dicha prensa, de maderas de algarrobo de 1/6 vara en cuadro, con bisagras de fierro; la horca donde está el husillo de maderas de ciprés de $1 / 3$ vara en cuadro, solera enterrada de 4 varas de alto y el husillo de madera de algarrobo con 3 cinchos de fierro y gorrón, la tuerca de maderas de espino de cerca de $1 / 2$ vara de ancho y grueso, $21 / 4$ varas de largo con cinchos de fierro con sus puntales de maderas de canelo y roble; aquí se agrega el repuesto de maderas de algarrobo en bruto para refaccionar el todo o parte de la dicha prensa. Todo en $\$ 300^{25}$.

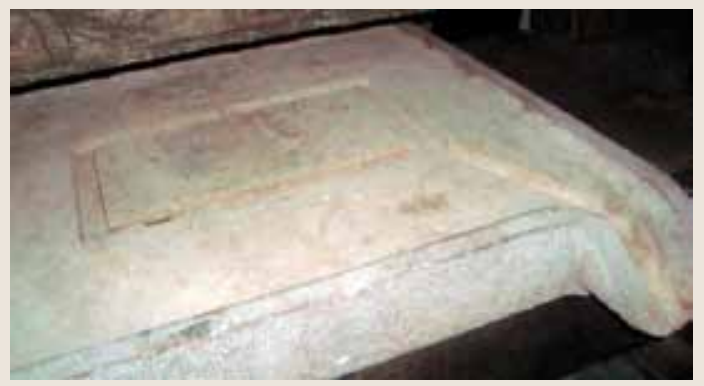

Figura 14. Piquera de piedra con canal en su contorno. Foto: PAL, Hacienda de San Lorenzo, Estado de Coahuila, México, julio 2009.

Resulta interesante el nivel de complejidad que alcanzaron las instalaciones de husillos y prensas que se encontraban en las bodegas del Reino de Chile en el siglo XVIII. El documento muestra el cuidado de los viticultores para montar el equipamiento y, asimismo, la capacidad de los notarios y tasadores para identificar cada uno de estos elementos y de describirlo en los inventarios.

${ }^{25}$ Tasación del sitio de Agustín del Castillo, Santiago, 1785. AN, FJS, Legajo 226, Pieza 7, Folios 27 v- 28. 


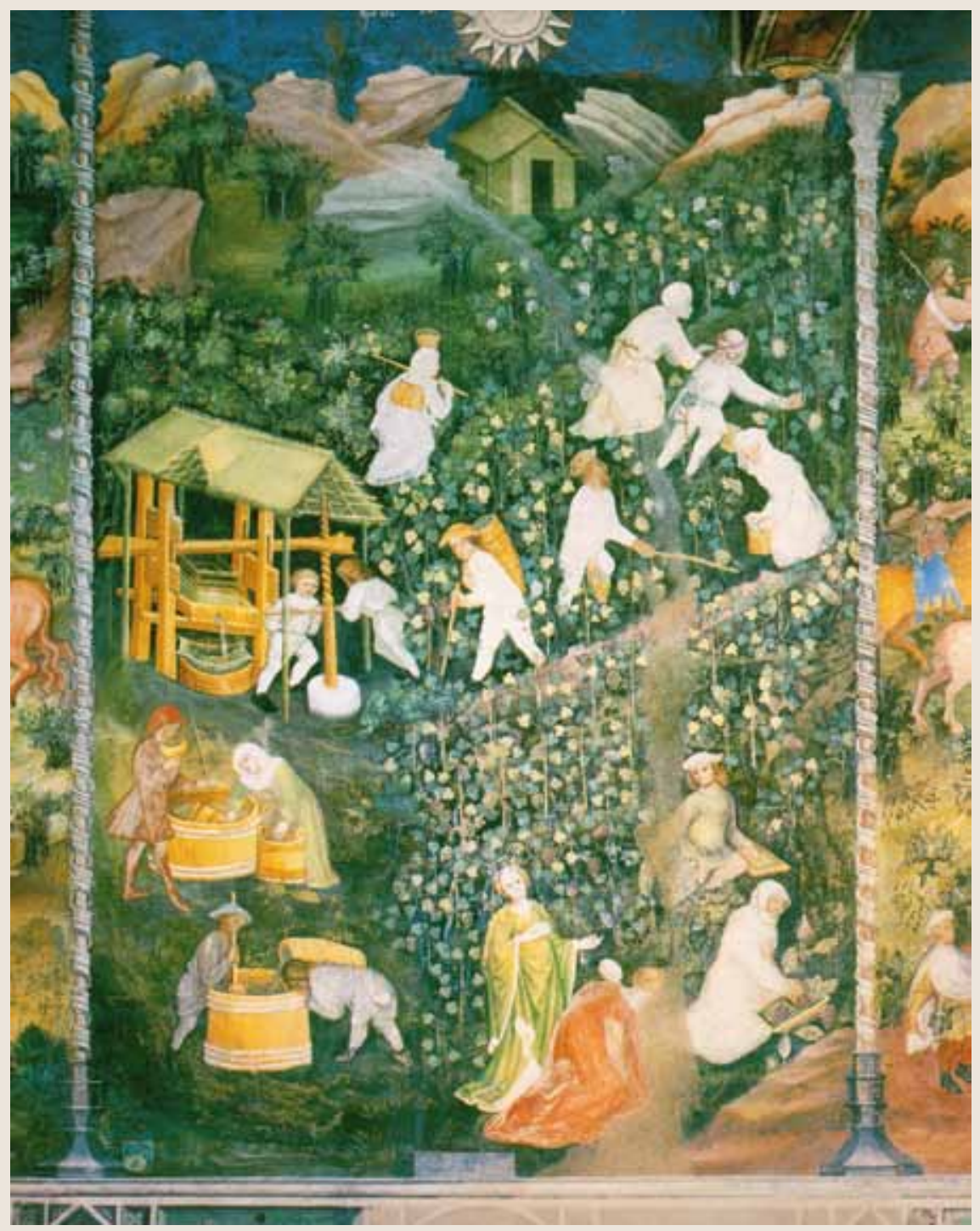

Figura 15. Vendimia europea (octubre en el hemisferio norte); lagares de madera, prensa de husillo y viga. Fuente: Miret (2005).

Sin embargo, las instalaciones y equipamiento de la viticultura colonial chilena, al parecer, sufrieron un retroceso en el siglo XIX. Al menos así se desprende de las observaciones de Claudio Gay, a mediados de esa centuria. $\mathrm{Al}$ referirse a los métodos de obtención del mosto, el observador señaló: 
las uvas pisadas que quedan en el lagar se pasan a otro por medio de unas canastas llamadas pescadores y se colocan sobre el cincho, especie de tejido de gruesas varillas con látigo para darle más fuerza. Luego que este cincho es bien cargado, se le asientan tablas sobre las que se ponen muchas piedras para hacer rendir al orujo todo el licor restante. Esta es la prensa generalmente usada en Chile y que por su poca fuerza debe necesariamente dejar mucho jugo en los orujos. Por este motivo se pone otra vez en el lagar para volverlo a pisar, o bien se destina directamente a la destilación y como producen mucho aguardiente, esto compensa en algo la imperfección de tal prensa (Gay, 1855: 190-191).

Llama la atención que Gay no haya conocido los lagares con sus prensas de vigas y husillos. Es posible que el motivo de esta ignorancia haya sido escasez de información. O también pudo ocurrir que las instalaciones del ciclo colonial se hayan perdido después de la independencia, en el contexto de crisis, guerras civiles y otras dificultades.

\section{CALAFATE, BREA, YESO}

El mantenimiento de recipientes que fueron usados para elaborar y conservar el vino es una de las dimensiones más antiguas de la industria. Este tema ya era asunto de interés en los primeros manuales de agricultura que escribieron los romanos. Un buen ejemplo es la obra Res Rusticae (Acerca de la agricultura), escrita en doce tomos por el gaditano Lucio Juno Moderato Columela en el año 65 de nuestra era. Entre otras observaciones, el autor señala la práctica de revestir las vasijas con brea en su interior. También señala que los vinos de calidad eran los más puros y naturales. Sin embargo, la conservación del vino era un problema y se trató de solucionar con distintas formas. Entre ellas, "añadir brea a los mostos y al vino" (citado en Unwin, 2001: 157). De esta forma se fue construyendo la tradición de experimentar sobre el contacto del vino con otras sustancias, con vistas a mejorar el manejo de los caldos. Y estos aprendizajes se trasladaron no sólo al aprestamiento de la vasija sino también a los lagares.

Una tarea sensible en el uso de los lagares era prepararlos para estar en condiciones adecuadas para cumplir sus funciones, en vísperas de la vendimia. Esta tarea se llamaba calafateo. Pero antes de entrar en la actividad de los viticultores, conviene precisar los conceptos. El uso de esta palabra para describir la preparación de los lagares deviene del lenguaje de mar. Para los marinos del siglo XVII, calafate significaba "el que con mazo y escoplo 
aprieta las junturas de las tablas de los navíos y después los brea y aprieta de modo que no pueda calarlo el agua" (Covarrubias, 1995 [1611]: 233). Esta operación era muy complicada y costosa pues de ello dependía la vida útil de los barcos y se realizaba con brea. La brea era "cierto género de betún o empega artificial de sebo, pez, resina y otras cosas pegajosas con que calafatean los navíos" (Covarrubias, 1995 [1611]: 205). Con el tiempo, el calafate pasó a ser una rama especializada dentro del oficio de la carpintería (RAE, 1852: 121). Por la importancia de la actividad, el costo de los materiales y el oficio requerido en la mano de obra, no tardó en trasladarse, dentro de Chile, este mismo concepto para el cuidado y mantenimiento de los lagares.

La función del calafate era impermeabilizar. En los barcos se usaba para impedir el ingreso del agua. En los lagares y botijas, para evitar la pérdida del mosto o el vino. En ambos casos, la función era la misma. En efecto, en el espacio vitivinícola, en vísperas de la vendimia, se procedía a calafatear la bodega. Esta acción consistía en encerar los lagares y la vasija con brea y yeso. A diferencia del calafate de los barcos, en los lagares se usaba una brea muy delicada, con una propiedad principal: era insípida, para no alterar el sabor del vino.

La costumbre de embrear los recipientes dedicados al vino ingresó al cono sur a través de Perú en los siglos XVI y XVII. "El interior de tinajas y botijas debía ser impermeabilizado, 'empegado' con brea, una sustancia viscosa de origen vegetal, una resina que se obtenía de la madera de algunas coníferas. En ese tiempo se traía de Nicaragua (...) Tráense de Nicaragua 20.000 quintales de brea para beneficio de las botijas de vino (...) Más tarde se comenzó a utilizar para este fin la brea de Amotape, un producto mineral, derivado de la destilación de la hulla" (Soldi, 2006: 56).

En el Reino de Chile, la brea usada para calafatear los lagares era una cera vegetal. Se obtenía de una planta chilena nativa, pluchea absinthioides, comúnmente conocida como "brea". Esa planta crecía como maleza en Chile, sobre todo junto a ríos, arroyos y canales, en la región comprendida entre el río Salado (cerca de Copiapó) y el río Aconcagua, entre San Felipe y Santiago. "Normalmente la planta no supera los 1,40 metros de altura. El color de las hojas es verde pálido. La brea produce una característica resina pegosa, especialmente las plantas adultas. La resina de la brea se usaba en tiempos pasados como lubricante y en la construcción"26. La planta presenta un tallo delgado y largo, con pequeñas hojas dentadas, con forma 2009].

${ }^{26} \mathrm{http}: / /$ www.geovirtual.cl/Museovirtual/Plantas/Brea01esp.htm [Consultado 7 de julio de 
de triángulo isósceles, y textura muy carnosa. Las autoridades españolas concedieron a los indios el monopolio para explotar y comercializar la brea de estas plantas ${ }^{27}$.

La costumbre de calafatear los lagares con brea y yeso se difundió entre los viticultores de ambos lados de la cordillera. $\mathrm{Al}$ parecer, sus orígenes estuvieron en Chile Cisandino debido a la familiaridad con las costumbres de mar y a la abundante disponibilidad de la brea vegetal. Pero el constante ir y venir de los arrieros a través de la cordillera no tardó en difundir estas prácticas en la provincia de Cuyo, en Chile Trasandino. Como resultado, en el cluster vitivinícola de las actuales zonas centrales de Argentina y Chile se compartió esta costumbre de calafatear los lagares. Así se refleja en los registros de "lagar calafateado de brea y yeso"28. El uso de la brea como acondicionador se utilizó tanto en lagares de cuero como en los de material no perecedero.

Las chacras y haciendas vitivinícolas tenían, entre sus materiales de trabajo, brea y yeso, sobre todo antes de la vendimia. El caso de la hacienda de don Miguel de Arizmendi, con los detalles que se ventilaron en un juicio, arroja luz sobre estos materiales y su uso. La chacra de don Miguel de Arizmendi tenía una pequeña viña de 4.100 cepas frutales. Era un viñedo de buena calidad, valuado a cinco reales por cepa y cercado de tapias. Las instalaciones de elaboración incluían los siguientes elementos: "un cuarto grande de bodega y lagar, tres tinajas enterradas y acondicionadas, un cuarto con su división adentro y su puerta; un cuarto de media agua, seis perales, una higuera y el sitio en que está edificado, todo ello tasamos en $\$ 1.230$ "29. Dentro de la bodega estaban los materiales para la vendimia, incluyendo 10 arrobas y 16 libras de brea cocida y varias fanegas de yeso. El yeso se valuaba a ocho reales la arroba y la brea costaba $\$ 5$ por arroba; tal vez su elevado costo se debía al flete que cobraban los arrieros para transportarla desde el otro lado de la cordillera. Buena parte de estos materiales se usaron en la vendimia de 1748 para calafatear el lagar y la vasija. Según el albacea, el padre Francisco Correa de Saá, se emplearon cinco fanegas de yeso y nueve arrobas con una libra de brea para esa vendimia, con un costo

\footnotetext{
${ }^{27}$ Referencia del doctor Hernán Cortés, interconsulta del 7 de julio de 2009.

${ }^{28}$ Inventario de bienes de San Francisco de la Selva, Copiapó, 31 de agosto de 1767. AN, FJCH, Volumen 8, Pieza 2, Folio 173.

${ }^{29}$ Tasación de bienes de Miguel de Arizmendi, Mendoza, 21 de junio de 1748. AHM, Época Colonial, Folio 178 v.
} 
de $\$ 50$ con $4 \frac{1 / 4}{\text { reales }^{30}}$. Algo distinta fue la declaración del capataz, Vicente Martínez, el cual relató su tarea en los siguientes términos:

En la bodega de dicha viña había un noque lleno de yeso quemado y lo hizo moler para componer el lagar porque estaba descompuesto. Asimismo, se gastó seguro en la primera lagarada que se hizo, se echó 1 1/2 fanega que cuando salió de la hacienda quedó otro poco de dicho yeso en la bodega, chancado, como cosa de 1 fanega. Asimismo, gastó un poco de brea en embrear dicho lagar y embrear tres tinajas para echar el vino y que juntamente embreó el pilón que no puede regular lo que se pudo gastar ${ }^{31}$.

Más allá de este sonado pleito, en el cual tomó parte activa el comisario de la Inquisición, el padre Francisco Correa de Saá, lo importante para los objetivos del presente estudio, es dar cuenta del uso de estos materiales para tratar de obtener mejores condiciones para el desarrollo de la actividad vitivinícola en la región analizada.

\section{LAGARES DE MATERIAL PERECIBLE}

Además de los lagares fijos de material permanente, en la viticultura tradicional de Argentina y Chile se usaron también lagares móviles y de material perecedero. Dentro de este grupo se detectaron 537 unidades, incluyendo 24 lagares de madera, dos de cestones y 511 de cuero.

Con menor frecuencia se usaron los lagares de lienzo y de cestones. En cierta forma, se trataba de una prolongación de los cestones que se usaban para el acarreo de la uva, desde la viña hacia el lagar. Esta actividad se realizaba usando tracción a sangre, mediante el servicio de las mulas cestoneras. En algunos casos, se usaron los mismos materiales para construir lagares. De todos modos, fueron situaciones muy excepcionales. Entre los pocos registros hallados, cabe mencionar la viña de Antonia Coria (Mendoza, 1765), donde se encontraron dos lagares de cestones que, por estar bien tratados, se valuaron a 12 reales $^{32}$. También fueron escasos los lagares

${ }^{30}$ Inventario de bienes de Miguel de Arizmendi, Mendoza, 8 de julio de 1748. AHM, Época Colonial, Sección Judicial, Carpeta 233, Documento 4 Folios 18, 21 v y 22.

${ }^{31}$ Declaración del capataz Vicente Martínez, Mendoza, 6 de julio de 1748. AHM, Época Colonial, Sección Judicial, Carpeta 233, Documento 4, Folios 28v-29.

32 Tasación de bienes de Ignacio Moyano y Antonia Coria, Mendoza, 10 de diciembre de 1765. AHM, Carpeta 239, Documento 11, Folio 13 v. 
de lienzo. Se usaron en el virreinato de Perú para solucionar el problema de los viticultores sin lagar, ante la apremiante situación que debían enfrentar en la vendimia, pues si no pisaban la uva a tiempo, podían perderla por su rápido deterioro. La iniciativa la tomó un indígena que tenía un pequeño parral pero carecía de lagar; en estas circunstancias, pisó la uva en unos costales de lienzo. Luego los españoles adoptaron este método como propio en esa región, pero siempre en pequeña escala (Soldi, 53). Los lagares de lienzo no se usaron en Chile y Cuyo. Pero este antecedente inspiró a los viticultores de la región para resolver el problema de falta de lagar con materiales disponibles: en vez de lienzo usaron cueros.

\section{GEOGRAFÍA GENERAL DE LAGARES PERMANENTES Y PERECEDEROS}

Si se realiza el cruce entre la localización geográfica y los lagares permanentes y perecederos, se detectan datos de interés. Sobre todo porque se hace visible la relación inversa entre los dos tipos de lagares: a mayor desarrollo del lagar de cuero, menor de lagar permanente y viceversa. Ya se ha identificado a Cauquenes, Parral, San Fernando y San Felipe como fuertes centros de lagares de cuero. Precisamente esos lugares son los que menos lagares permanentes tuvieron. Y, por el contrario, donde menos lagares de cuero se hallaron, había mayor cantidad de lagares de piedra o ladrillo.

Las capitales fueron los principales centros de desarrollo de los lagares permanentes, tanto de Chile Cisandino como de Chile Trasandino. En efecto, en la falda occidental de los Andes, el principal centro de construcción de lagares permanentes estuvo en Santiago, mientras que del otro lado de la cordillera, igual papel cupo a Mendoza.

En efecto, funcionaban en Santiago 50 lagares permanentes, lo que representa el 34,4\%, mientras que Mendoza tenía 43 unidades (29,6\%). Entre esas dos ciudades concentraban casi dos tercios del total de lagares permanentes de toda la región vitivinícola estudiada. Seguían en importancia San Juan y La Serena. Ésta tenía 26 lagares permanentes (17,9\%) y aquélla 13 unidades $(8,9 \%)$. Muy escasas eran estas instalaciones en San Felipe y San Fernando: apenas $6(4,1 \%)$ y $7(4,8 \%)$ respectivamente; en tanto que en las regiones vitivinícolas del sur Valle Central (Parral, Cauquenes), no había lagares permanentes porque, como ya se ha señalado, predominaba allí el lagar de cuero. 

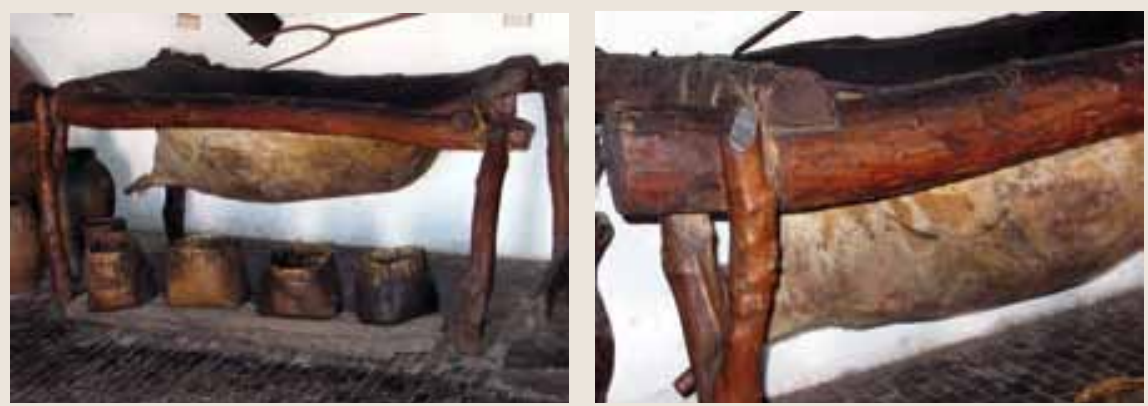

Figura 16a y b. Lagar de cuero. Museo La Rural.
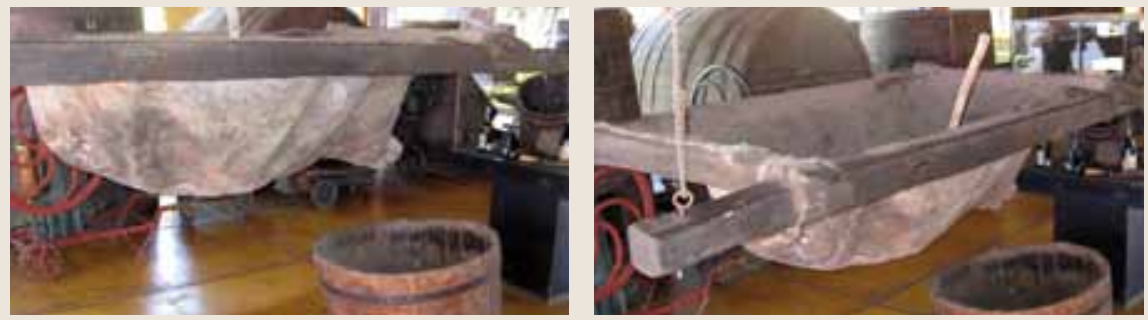

Figura 17a y b. Lagar de cuero. Museo Santa Cruz.
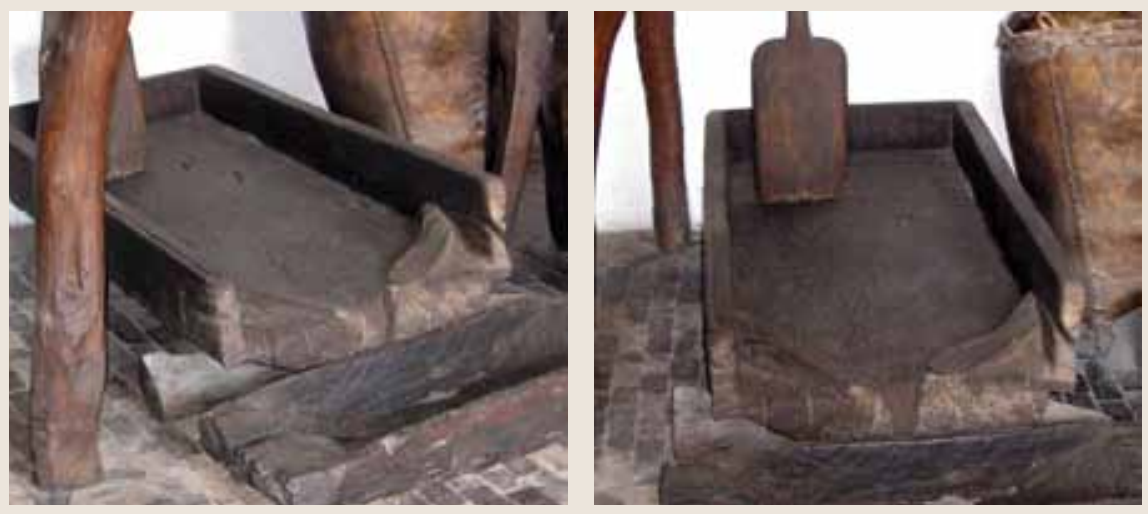

Figura 18a y b. Lagar de madera. Museo La Rural.

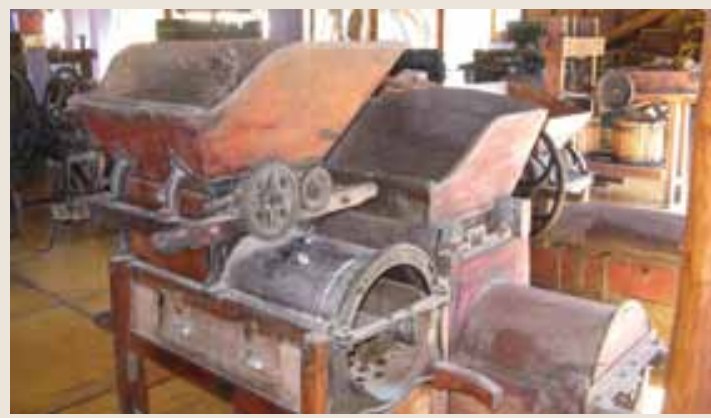

Figura 19. Moledora de uva mecánica. Este tipo de máquina se usó en Chile desde fines del siglo XIX hasta buena parte del XX.

Colección: Museo de Santa Cruz. 


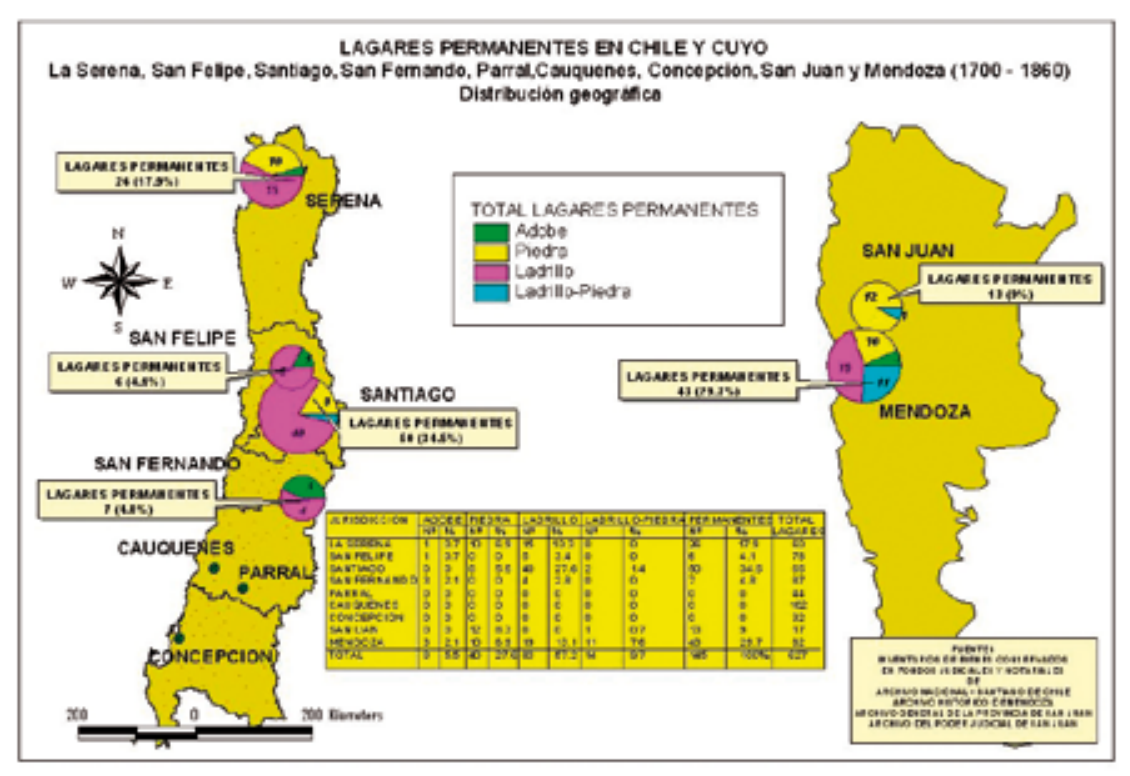

Figura 20. Lagares permanentes en Chile y Cuyo.

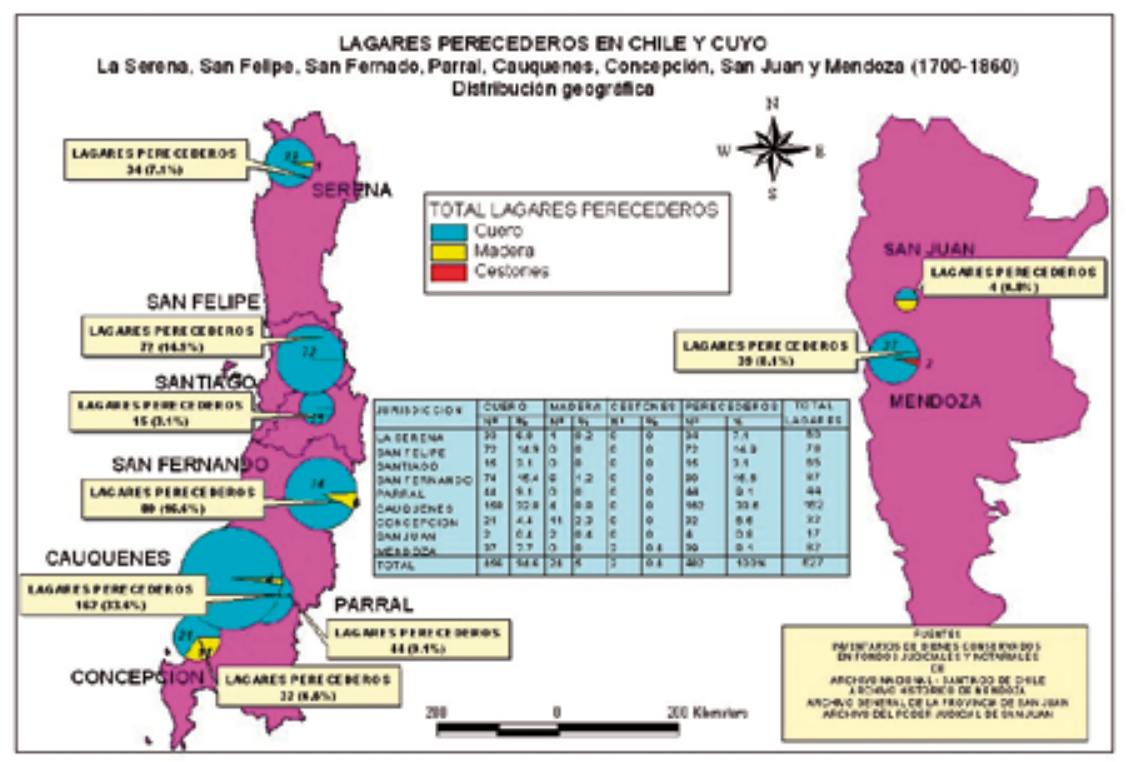

Figura 21. Lagares perecederos en Chile y Cuyo. 
Tabla I. Lagares en Chile y Argentina, siglos XVIII-XIX. Discriminación por lugar geográfico.

\begin{tabular}{|c|c|c|c|c|c|c|c|c|c|c|c|c|}
\hline \multirow[b]{2}{*}{ LUGAR } & \multicolumn{6}{|c|}{ LAGAR PERMANENTE } & \multicolumn{5}{|c|}{ LAGAR PERECEDERO } & \multirow{2}{*}{$\begin{array}{l}\mathbf{T} \\
\mathbf{O} \\
\mathrm{T}\end{array}$} \\
\hline & Adobe & Piedra & Ladrillo & $\begin{array}{l}\text { Ladrilo } \\
\text { y } \\
\text { piedra }\end{array}$ & Subtot & $\%$ & Cuero & Madera & Cestones & Subtot & $\%$ & \\
\hline La Serena & 1 & 10 & 15 & -- & 26 & 17.9 & 33 & 1 & -- & 34 & 7.2 & 60 \\
\hline San Felipe & 1 & - & 5 & -- & 6 & 4.1 & 72 & -- & -- & 72 & 15.2 & 78 \\
\hline Santiago & -- & 8 & 40 & 2 & 50 & 34.4 & 15 & -- & -- & 15 & 3.1 & 65 \\
\hline $\begin{array}{l}\text { San } \\
\text { Fernando }\end{array}$ & 3 & -- & 4 & -- & 7 & 4.8 & 129 & 6 & -- & 80 & 16.9 & 87 \\
\hline Parral & -- & -- & -- & - & -- & 0.0 & 44 & -- & -- & 44 & 9,3 & 44 \\
\hline Cauquenes & -- & -- & -- & -- & -- & 0.0 & 158 & 4 & -- & 162 & 34,4 & 162 \\
\hline Concepción & -- & -- & -- & -- & -- & 0.0 & 21 & 11 & -- & 32 & 6,7 & 32 \\
\hline San Juan & -- & 12 & -- & 1 & 13 & 8.9 & 2 & 2 & -- & 4 & 0,8 & 17 \\
\hline Mendoza & 3 & 10 & 19 & 11 & 43 & 29.6 & 37 & -- & 2 & 39 & 8,2 & 82 \\
\hline total & 8 & 40 & 83 & 14 & 145 & 100 & 511 & 24 & 2 & 537 & 100 & 682 \\
\hline$\%$ & 5.5 & 27.5 & 57.2 & 9.6 & 100 & & 94.4 & 5,0 & 0,4 & 100 & & \\
\hline
\end{tabular}

Fuente: Elaboración propia a partir de: Fondo Notarial de Parral, Fondos Judiciales de Cauquenes, San Fernando, Santiago, San Felipe y La Serena y Fondo Jesuitas de Chile (AN). Protocolos de Escribanos y Sección Judicial (AHM). Fondo Histórico de San Juan (APJSJ).

\section{EL LAGAR COMO ESPACIO SOCIAL: LA PISADA DE LA UVA}

Además de su significado dentro de las instalaciones y el equipamiento de las bodegas para elaborar el vino, el lagar era un importante espacio social, sobre todo en tiempos de cosecha y vendimia. Particularmente, la pisada de la uva era un acto que iba mucho más allá de la mera transformación de la uva en mosto para elaborar el vino: era un acontecimiento de significativa popularidad y convocatoria, con connotaciones festivas.

La pisada de uva con pies de hombre fue el método más utilizado en vitivinicultura, desde la antigua cultura egipcia hasta fines del siglo XIX. Todavía en la década de 1860, el experto francés Jules Guyot, autoridad mundial en la materia, recomendaba este método como el mejor. Como fundamento aseguraba que los pies bien lavados eran tan adecuados para pisar la uva, como las manos bien lavadas lo eran para preparar los alimen- 
tos. Además, el autor señalaba que los pies de hombre son mejores que las máquinas porque ejercen la presión justa para pisar la uva sin romper las pepitas (Guyot, 1861: 232-233). En cambio, al moler la uva con lagares mecánicos, se rompe también la pepita, con lo cual se derraman aceites amargos en el mosto. A pesar de esta desventaja, las máquinas ganaron y, desde fines del siglo XIX, la pisada con pie de hombre quedó fuera de la corriente principal de la industria vitivinícola (Rojas, 1891: 153). Durante cerca de cien años, la uva se molió en lagares mecánicos que lograron bajar los costos, pero sólo para generar vinos amargos. Esta situación se comenzó a revertir en las últimas décadas del siglo XX, con innovaciones tecnológicas que permitieron resolver el problema de la pepita, con sistemas de vacío y otros métodos. De todos modos, dentro del período estudiado en el presente artículo, la pisada de la uva se hacía con pie de hombre.

La pisada de la uva a pie se realizó tanto en lagares de material permanente como en lagares perecibles, incluyendo dentro de este grupo a los de madera y los de cuero. En el caso del lagar de cuero, la pisada de la uva a pie de hombre planteaba un problema técnico relevante: el peso. Ello planteaba un desafío para la construcción y conservación del lagar. Sobre todo para amarrar con fuerza el cuero al bastidor. Además, el peso de los pisadores aumentaba la tensión del cuero y, periódicamente, se producían roturas en el recipiente, que luego era necesario reparar. En algunos casos, la uva se pisaba en lagares provisorios, construidos con cueros apoyados en estacas. Un grabado ha representado esta modalidad, con dos esclavos afroamericanos que pisan la uva en un lagar provisorio de cuero. Este grabado se publicó en una obra de Draghi (1946), reeditada años después (2005). Fue valorado por la comunidad vitivinícola local, y se reprodujo este dibujo sobre cerámica.

El grabado del lagar de cuero y los pisadores tiene un elemento muy interesante para analizar porque permite ver la evolución de las representaciones de los protagonistas de la industria vitivinícola. Para ello, hay que comparar el grabado publicado por Draghi en 1946 y su copia exhibida en La Rural. A simple vista podría considerarse que se trata del mismo dibujo, pero basta observar con más detalle para descubrir las diferencias. Entre ellas se ha cambiado la identidad étnica de los protagonistas: en el grabado original, los pisadores son claramente afroamericanos, según se desprende del grosor de los labios, la forma de la cabeza y los cabellos ensortijados. En cambio, la representación del museo La Rural presenta a los pisadores blanqueados, con rasgos caucásicos (labios delgados, forma de la 


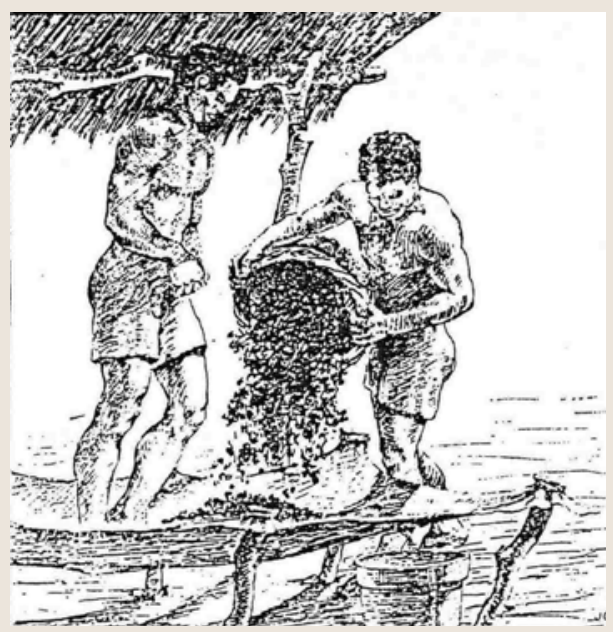

Figura 22a. Esclavos afroamericanos pisan la uva en un lagar provisorio de cuero. Grabado publicado en Draghi Lucero (1946).

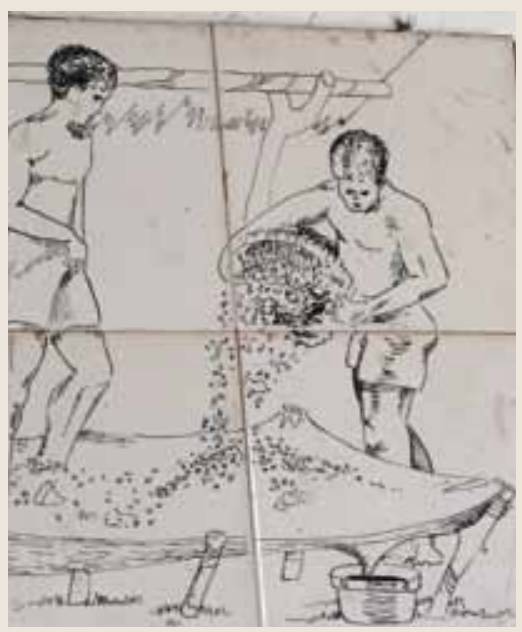

Figura 22b. La misma ilustración anterior copiada sobre cerámicas y exhibida en el museo La Rural.

cabeza más alargada, cabello ondulado, entre otros detalles). Como se sabe, el museo fue creado en 1940 por el viticultor Rodolfo Reina Rutini, con el objetivo de destacar la historia vitivinícola de Mendoza y el papel de los inmigrantes europeos en este proceso. La cerámica con la representación de los artesanos se colocó alrededor de 1985. Más allá de las intenciones del autor, el museo se construyó y desarrolló en un contexto dentro del cual la clase intelectual y empresaria de Argentina atribuía la casi totalidad de los méritos de la industria del vino a los inmigrantes europeos, a la vez que tendía a minimizar el aporte de los criollos, de la época colonial y de los afroamericanos en particular. En este contexto, los artistas contratados para elaborar esta copia de la escena de los pisadores interpretaron que la mejor opción era blanquearlos, tal vez para agradar a los dueños de la bodega y el museo de La Rural.

La pisada de la uva con pie de hombre era un oficio que tenía sus propias reglas. Uno de los problemas de los pisadores era mantener el equilibrio. Para no caerse, los pisadores necesitaban puntos de apoyo. El pisador podía tomarse de cuerdas ubicadas arriba del lagar, atadas a una viga o travesaño. Así se ha podido comprobar en las ilustraciones incluidas oportunamente en este trabajo: las representaciones del lagar egipcio (Figuras 6 y 7) y del lagar español del siglo XX (Figura 11). También se ha visto este sistema en 
un lagar tradicional de México (bodega del Vesubio, Parras, Coahuila) ${ }^{33}$. La opción era apoyarse en bastones o palos, o bien podían apoyarse unos con otros, tal como se percibe en las representaciones romanas (Figura 1).

La música era otro elemento importante de la pisada de la uva. Se usaron tanto instrumentos de percusión como de cuerdas y hasta de viento. En los lagares de las colonias fenicias del sur de España se usaba el doble aulós, instrumento de viento con dos cilindros de madera y lengüeta de caña. La literatura especializada indica también que, hasta mediados del siglo XX, todavía se usaba música afro para mejorar la actividad: "al roturar las uvas con los pies, para coger el ritmo se ayudan con un son propio de alguna danza africana" (Artola Beuzón, 2005: 68). También se usaban instrumentos musicales de cuerda, como la guitarra portuguesa (Figura 24).

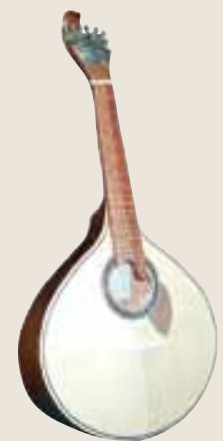

Figura 23. Ilustración C-7. Guitarra portuguesa como la utilizada en la representación.

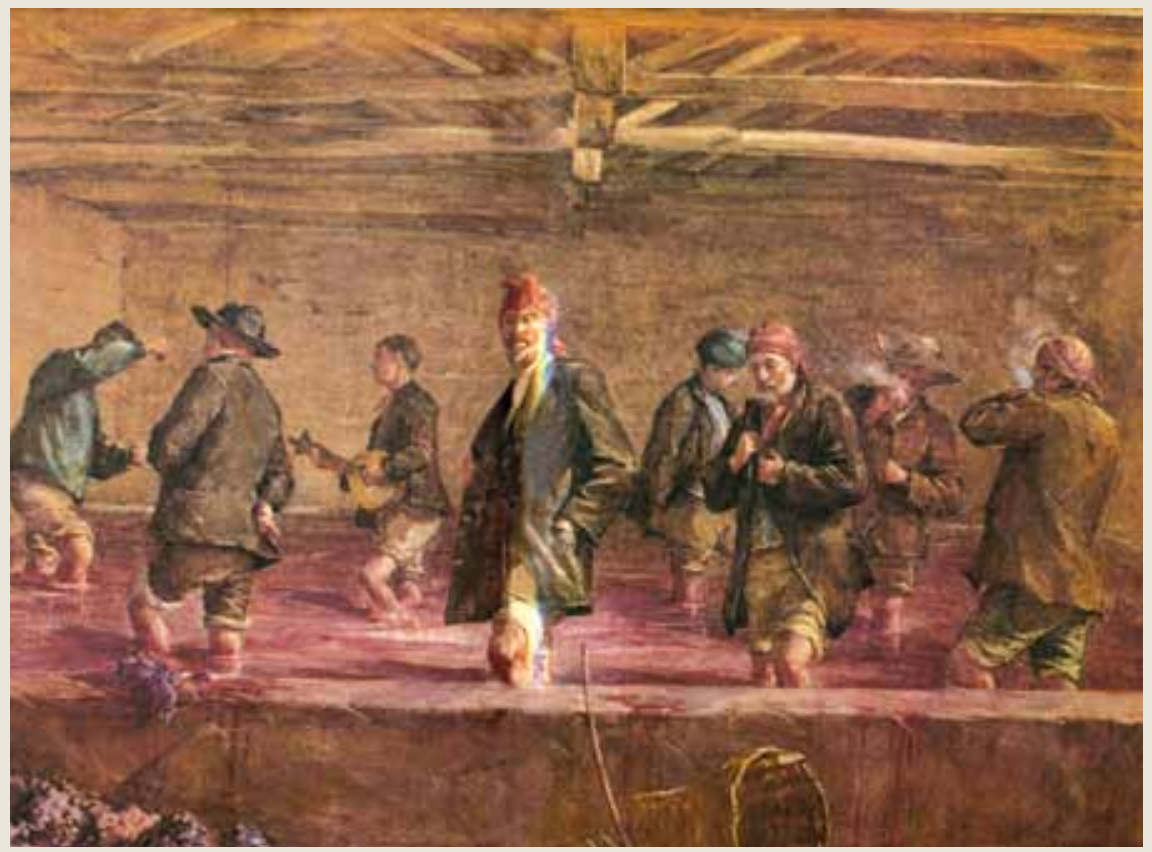

Figura 24. Pisada de la uva en un lagar de material permanente, probablemente en rivera del Duero, Portugal. Nótese la presencia de la guitarra portuguesa, con su particular clavijero de forma triangular. Fuente: Halley (1990).

\footnotetext{
${ }^{33}$ Visita realizada a Santa María de Parras, estado de Coahuila, México, 17 de julio de 2009.
} 
La música en la pisada de la uva también se desarrolló en el espacio latinoamericano. La región de Tarapacá fue un buen ejemplo. Entre los siglos XVII y XIX, en las áridas tierras del desierto de Atacama, se puso en marcha una singular viticultura, sobre todo en el oasis de Pica (Castro, 2009). A partir del siglo XX se produjo la desaparición de esa tradición vitivinícola regional. Sin embargo, el trabajo de historiadores y antropólogos ha permitido reconstruir aspectos relevantes de esa cultura, particularmente la pisada de la uva y su entorno de música y danza:

Organizaba la pisa con cuadrillas que se sometían a las órdenes de un ingenioso Guaycuru, quien, con una vara de granado en mano, improvisaba versos y cantos del lagar. Comenzaba con un cadencioso y suave canto de Yajalayajai, para apurar con un guainito y finalmente un ritmo brincador que aceleraba el escurrimiento y las caídas de aquellos que no se tomaban de las manos (Núñez, 1985: 4).

El texto resulta esclarecedor. El guainito es una danza propia del altiplano, llamada así en Bolivia, Perú y Ecuador; en el norte argentino se la conoce como carnavalito y en Chile se denomina trote. Se utilizan instrumentos de viento, cuerdas y percusión, sobre todo quena, charango y bombo, como síntesis de las tradiciones musicales altiplánicas y africanas. Sobre esta base se desarrolló una tradición, que explica la fiesta de la pisada de la uva que actualmente se realiza en Ica (sur de Perú), con el uso de instrumentos como cajón peruano (con membrana de madera), cencerro y bongó (instrumento de membrana animal, inspirado en el tambor africano).

El lagar y la pisada de la uva permitieron crear un alegre espacio social. Allí convergían los distintos actores sociales para coronar, en ambiente festivo, los trabajos culturales de todo el año en la viña: hombres y mujeres, adultos y niños, propietarios y trabajadores, esclavos y personas libres, blancos y negros; todos tenían curiosidad por estar presentes en ese momento. Algunos tocaban sus instrumentos musicales, mientras otros pisaban; un tercer grupo seguía adelante con la cosecha y descargando la uva en el lagar. Otros reunían el orujo para prensarlo. Se combinaba el trabajo con el juego. El ambiente de bullicio, música y alegría inundaba el ambiente. En ese contexto se generaban las condiciones para las fiestas de fin de cosecha $\mathrm{y}$, particularmente, las fiestas vendimiales. 


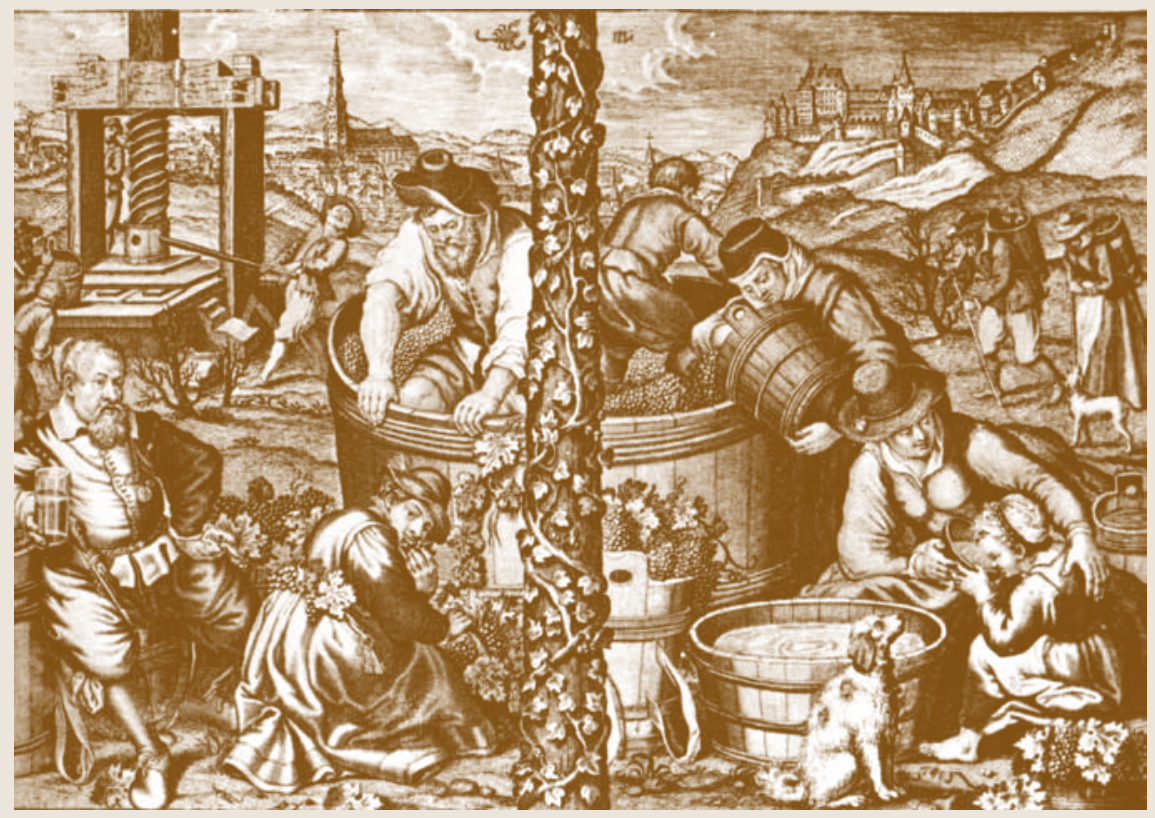

Figura 25. Grabado flamenco del siglo XVII basado en pintura de Kart Gustav Amling. Fuente: Piqueras 1986.

\section{INDUSTRIALIZACIÓN Y DECADENCIA DEL LAGAR ARTESANAL}

El proceso de industrialización de la vitivinicultura, iniciado a fines del siglo XIX, significó un cambio negativo en el uso de los lagares. Para bajar costos y elaborar mayor cantidad de vino en menor tiempo, se sustituyó la pisada de la uva con pie de hombre por los métodos mecánicos. Por este camino se experimentó un notable retroceso en el plano de la calidad.

A pesar de ello, los antiguos lagares de cal y ladrillo se usaron hasta bien entrado el siglo XX. En 1931 un observador señaló que "los lagares son pozos de cal y ladrillo construidos sobre el suelo, generalmente bajo el alero de un edificio. Son de poca profundidad-muy a menudo de 1,50 m-y ocupan todo el espacio disponible en la media agua debajo de la cual están edificados" (Canu, 1931: 163). En cierta forma, se seguían usando las mismas instalaciones que 200 años antes, pero con una diferencia importante: en el período tradicional el lagar se usaba para pisar la uva y no para realizar la fermentación. En cambio, en el siglo XX la fermentación se realizaba en este mismo recipiente, debido al uso de las pesadas máquinas moledoras de uva.

En efecto, en el primer tercio del siglo XX las viñas incorporaron la má- 
quina moledora de uva. Se llamaba "vendimiadora" y consistía en una gran caja de madera, con unos rodillos afilados en su interior, movidos por una manivela. El pesado armatoste se colocaba sobre los antiguos lagares de cal y ladrillo, sostenido sobre tablones de madera. La uva se volcaba dentro de esa caja, y los obreros movían la manivela para moler las bayas. El escobajo se retiraba y se colocaba en los costados. El mosto caía al lagar de cal y ladrillo y allí se realizaba la fermentación.

El empleo de este método tenía notables problemas. En primer lugar, al molerse mecánicamente la uva, además de la baya, se rompía también la pepita, con lo cual se derramaban los aceites amargos en el mosto. Además, se producían problemas de higiene y de fermentación. La moledora de uva era una máquina muy pesada y se movía a pulso. Por el gran esfuerzo que significaba desplazarla y ante el riesgo de descuadrarla, se procuraba mantener la máquina el mayor tiempo posible en ese lugar. La moledora de uva permanecía varios días en el mismo sitio, sin trasladarse para limpiarla. Y tampoco se podía lavar en ese lugar, para no afectar el mosto. "No se puede lavar la máquina porque toda el agua sucia tendrá que caer en la misma vendimia molida. Por la mañana del día siguiente, las primeras completadas de uva arrastran hacia el lagar toda la mugre del día anterior, y también todos los malos gérmenes que durante la noche han principiado a desarrollarse junto con las levaduras. Cuando el lagar está lleno, es menester cambiar la máquina y correrla hacia el lagar vecino, lo que no se hace sin que todo el barro azucarado, pegado sobre los tablones, vaya cayendo dentro del lagar con todas las consecuencias del caso" (Canu, 1931: 163).

La fermentación, entonces, se realizaba en malas condiciones. El mencionado especialista lo explicaba en los siguientes términos:

Todos estos lagares presentan, a la vez, poca profundidad y gran superficie por su ancho y su largo. Cuando la fermentación principia, las películas son arrastradas hacia la parte superior del lagar por el gas carbónico que se desprende. Vienen a formar una delgada capa esponjosa que sale del mosto, constituyendo el sombrero. Mientras la parte inferior de esa masa porosa de orujos se mantiene constantemente humedecida por un líquido caliente, cuya graduación alcohólica va aumentando poco a poco, su parte superior se encuentra largamente expuesta al aire. No puede haber condiciones más favorables para el desarrollo de la bacteria acética y por consiguiente para la acetificación del líquido. Así, en la parte superior, las levaduras suficientemente aireadas, que trabajan normal y activamente, elevan la temperatura del líquido que las rodea y las películas se ven lavadas, agotadas, por ese líquido de sus sustancias solubles. $\mathrm{Al}$ contrario, en las capas inferiores, las levaduras insuficientemente ai- 
readas no se multiplican: la temperatura queda baja; la disolución de los principios solubles de la pequeña cantidad de orujos allí presentes se hace de un modo imperfecto. En estas condiciones la irregularidad de la fermentación es tal que, al día siguiente de generalizarse la fermentación en el lagar, se puede constatar que el vino próximo al sombrero ya tiene 5 grados y más (de alcohol), mientras que abajo el mosto está aún frío y sólo contiene pequeñas cantidades de alcohol (Canu, 1931: 164).

El proceso de sustituir la artesanal pisada de la uva por las máquinas de moler la uva en forma mecánica, ampliamente difundido en el siglo XX, significó cambiar aspectos centrales de la naturaleza de la cultura de la vid y el vino. La industrialización generó la posibilidad de elaborar mayor cantidad de vino en menor tiempo y a menores costos, pero de una calidad notablemente inferior.

\section{CONCLUSIÓN}

Entre mediados del siglo XVI y mediados del XIX la viticultura tradicional de Chile y Argentina utilizó lagares de distintos materiales, costos y tamaños. Se desarrollaron diferentes alternativas, tratando de aprovechar los materiales disponibles y los recursos que los distintos sectores sociales podían invertir. Lo más notable es la diversidad de lagares, lo cual muestra que el mundo de la viticultura era notablemente heterogéneo, geográfica, cultural y socialmente. Sobre todo por las buenas perspectivas de movilidad social que este modo de producción ofrecía para los campesinos pobres.

El presente estudio examinó 682 lagares, incluyendo 537 de materiales perecederos y 145 lagares permanentes. Considerando los lagares con información sobre la naturaleza de sus materiales, los perecederos representaban tres cuartas partes del total $(74,4 \%)$, mientras que los lagares de material permanente comprendían el cuarto restante $(24,5 \%)$. Naturalmente, los lagares perecederos eran más numerosos, pero precarios y baratos. Los lagares permanentes eran más valiosos y su vida útil era más prolongada.

Dentro de los lagares perecederos había 511 lagares de cuero, lo cual representaba el 95\% de esa categoría; seguían los 24 lagares de madera (4\%) y los dos de cestones $(0.3 \%)$. Por lo tanto los lagares perecederos fueron en total 537. En el grupo de lagares permanentes se registraron 83 lagares de ladrillo (57,2\%), 40 lagares de piedra (27,5\%), 14 lagares mixtos de piedra y ladrillo $(9,6 \%)$ y apenas 8 de adobe (5,5\%), para totalizar 145 . 
En cuanto derivación del lagar de lienzo peruano, el lagar de cuero fue la gran innovación de la viticultura tradicional del Cono Sur. No se usó en otras regiones de América Latina, como México y Perú. Durante los dos primeros siglos de historia colonial tampoco se conocieron en las actuales repúblicas de Chile y Argentina. Fue un invento de la década de 1740. Apenas surgió, se comenzó a difundir por las distintas viñas de la región. Se detectaron 446 lagares de cuero, lo cual muestra una notable presencia en la viticultura tradicional de Argentina y Chile.

Desde el punto de vista geográfico, el lagar de cuero reinó sobre todo en las viñas al sur del río Maule. En Parral, Talca, Cauquenes y la cuenca del Itata, casi la totalidad de los lagares eran de cuero. En cambio, en las capitales (Santiago y Mendoza) predominaban los lagares de material permanente, sobre todo ladrillo y piedra. La principal característica de San Juan fue el amplio uso de la piedra laja.

El lagar de cuero fue el punto de contacto entre la viticultura y la ganadería. La profunda tradición ganadera del Valle Central de Chile se entrelazó con la industria de la vid y el vino mediante, justamente, los lagares de cuero. Como se ha señalado, en la primera mitad del siglo XVIII el Partido del Maule tenía dos terceras partes de su riqueza en la ganadería, un sexto en esclavos y el sexto restante en viticultura. Esta situación era bastante difundida en buena parte del Valle Central, sobre todo al sur del Maule. Y éste fue, precisamente, el área de mayor desarrollo de los lagares de cuero.

La amplia disponibilidad de cueros significó que el lagar de este material era un equipamiento de costo relativamente bajo. Como resultado, el lagar de cuero fue una innovación con fuerte significado social, pues hizo posible que los pequeños viticultores pobres pudieran disponer de sus propias instalaciones para pisar la uva y elaborar el vino. Basta señalar que un lagar de ladrillo o de piedra tenía un valor que, por lo general, superaba los $\$ 150$, mientras que un buen lagar nuevo de tres o cuatro cueros rondaba los $\$ 10$. Evidentemente, el uso de este material ponía el lagar al alcance de un mayor número de viticultores, sobre todo los más pequeños.

Los lagares de cuero variaban en tamaños y precios. Los más usados eran los pequeños, de uno o dos cueros; de esas medidas eran el $62 \%$ del total. Seguían los lagares medianos, de tres, cuatro o seis cueros, los cuales representaban el $31 \%$ de los casos. Con menos frecuencia se usaban lagares mayores, de 8, 10, 12 ó 14 cueros (5\% del registro). El valor guardaba relación con el tamaño. Los lagares nuevos costaban entre $\$ 2$ y $\$ 3$ por cuero. Posteriormente, el lagar comenzaba a perder valor a medida que se usaba 
y desgastaba. Por supuesto que, cuando mejor era la calidad del mantenimiento, el lagar lograba conservar una mejor capacidad y valoración.

Además de los lagares de cuero, también se usaron lagares de madera. Fueron una continuidad de los tradicionales lagares europeos y se usaron a ambos lados de la Cordillera de los Andes. El más antiguo data de comienzos del siglo XVII en La Serena y el último corresponde a Mendoza, a fines del XIX. De todos modos, el lagar de madera fue muy poco usado en la región estudiada, lo mismo que el lagar de cestones.

Los lagares de material permanente abrieron el camino para la búsqueda de una viticultura de mayor calidad. En la región estudiada se usaron lagares de cal y ladrillo, lagares de piedra y lagares mixtos, integrando piso de piedra con paredes de ladrillo. Dentro del contexto regional, los lagares de material permanente de Chile y Argentina tuvieron algunos puntos de continuidad con los de Perú, pero también sus diferencias.

Dentro de los lagares permanentes, los más difundidos fueron los lagares de ladrillo. Los más antiguos corresponden a La Serena, a comienzos del siglo XVII. Poco después llegaron a Santiago y, a mediados del XVIII, los jesuitas los introdujeron en Cuyo. En el siglo XIX los lagares de cal y ladrillo alcanzaron una difusión importante, sobre todo en Mendoza y Santiago. En menor medida estuvieron presentes en San Felipe y La Serena.

Los lagares de piedra tenían varias modalidades. Los más difundidos eran los lagares de calicanto (16) y de piedra laja (14); en menor medida se registraron los lagares de cascajo, ripio o de piedras labradas de sillería (7). La geografía y cronología de los lagares de cal y canto siguió un camino paralelo a los lagares de cal y ladrillo. Comenzaron a usarse en La Serena, a comienzos del siglo XVII. De allí pasaron pronto a Santiago y luego, a mediados del XVIII, ingresaron a Mendoza. Igual que en el caso de los lagares de cal y ladrillo, prácticamente no se usaron lagares de calicanto en la mitad sur del Valle Central.

La experiencia acumulada por la viticultura colonial en el campo de los lagares permanentes, con lagares de ladrillo por un lado y lagares de piedra por otro, generó las condiciones para un paso adelante: los lagares mixtos con piso de piedra y paredes de ladrillo. El primer antecedente se registró en Renca, cerca de Santiago; fue un ensayo de dos modestos lagares de piedra y ladrillo. Pero esta innovación fue desarrollada con estándares más altos de calidad por una mujer viticultora, doña Ana María Guevara, y el registro corresponde a San Juan (1790). Fue el mayor nivel de desarrollo de la técnica de construcción de lagares en el período tradicional de la viticultura de Argentina y Chile. Sobre esta base se construyeron los mejores 
lagares, con paredes de ladrillo y piso de piedra laja o de sillares de piedra labrada. Posteriormente, esta novedad se difundió y fue adoptada por los viticultores varones.

El empleo de materiales de calidad en la construcción de lagares permanentes tuvo un significado relevante, sobre todo porque los viticultores del entonces Reino de Chile (actuales Chile y Argentina cuyana) exhibieron una actitud de inversión de la renta en el mejoramiento de las instalaciones y equipamiento productivo. Esos grupos humanos mantuvieron un estilo de vida modesto y sus ganancias las volcaban a la producción y no al consumo. Sus casas eran de adobe y sus bodegas tenían lagares de ladrillo o de piedra. Se fue construyendo, así, una cultura del ahorro, la inversión y la postergación del consumo. Por este camino esos viticultores contribuyeron a construir una sociedad orientada a la movilidad social y la prosperidad económica a partir de la cultura del trabajo, el esfuerzo y la innovación.

Los lagares de material tenían medidas bastante estandarizadas. A diferencia de Perú, donde los lagares eran de planta cuadrada, redonda o rectangular, en Chile y Argentina sólo había lagares rectangulares. Su largo oscilaba entre $4 \frac{1}{1 / 2}$ y 8 varas. El ancho variaba entre $2 \frac{1 / 2}{2}$ y $5 \frac{1}{1 / 2}$ varas. Y la profundidad era de entre $3 / 4$ y 1 vara. También existieron lagares mayores y menores de estas medidas, pero sólo fueron casos excepcionales. Entre el 80 y el $90 \%$ de los lagares se circunscribían dentro de las variaciones señaladas arriba. Las fuentes también entregaron información sobre los pilones, esos receptáculos que recibían el mosto después de la pisada de la uva en el lagar. El 90\% de los pilones tenía entre 10 y 50 @ de capacidad.

Igual que ocurría con los lagares de cuero, los lagares de material permanente sirvieron para extender lazos entre la viticultura y otras industrias. Estas instalaciones se usaban para curtidurías de cuero, teñido de ropa y saladeros. La industria del vino contribuyó, de esta manera, a extender la dinámica de elaboración de materias primas hacia otras actividades.

Con respecto a los precios, los lagares de material también ofrecieron datos de interés. Se registraron los precios de 74 lagares, lo cual permitió detectar los patrones. Los lagares se agrupaban en tres niveles: bajo rango, intermedio y alto rango. Los lagares de bajo rango ( 46 casos) eran de materiales de menor calidad o bien, de calidad buena, pero viejos y maltratados. Sus valores oscilaban entre 20 y $\$ 90$. Los lagares intermedios (16 casos) oscilaban entre 100 y $\$ 225$. Y los lagares de alto rango (12 registros) cotizaban entre 300 y $\$ 680$. Los 74 lagares de material permanente con precio registrado acumularon $\$ 8.766$, con un promedio de $\$ 120$ por unidad. 
Los lagares del período tradicional de la viticultura de Argentina y Chile conformaron una parte compleja dentro del proceso de transformar la uva para elaborar el vino. Se usaron lagares rústicos y sofisticados, toscos y finos, baratos y caros. Había lagares de pequeños viticultores pobres y lagares complejos de mayor innovación. De alguna manera, la diversidad de los lagares representaba el cambiante y sorprendente mundo de la viticultura del Cono Sur de América.

Los lagares del ciclo tradicional de la viticultura han dejado de ser parte del equipamiento industrial de las bodegas y viñedos. Pero han resurgido como parte importante de las propuestas enoturísticas, incluyendo fiestas vendimiales y visitas a bodegas y viñedos. El lagar tradicional ha vuelto con fuerza a través del arte y particularmente del cine. La recreación de estas prácticas muestra la profundidad del lazo entre la cultura y el lagar.

El ciclo del lagar tradicional y la pisada de la uva se cerró con el siglo XIX. En el XX avanzó el proceso de industrialización, con el cual la uva dejó de pisarse con pie de hombre para molerse en forma mecánica. Durante cerca de un siglo predominó el nuevo método que permitía elaborar más cantidad de vino a menores costos, pero de peor calidad. En el último cuarto del siglo XX se puso en marcha una nueva etapa en la historia de la industria del vino en Chile. Se incorporaron nuevas tecnologías, más amigables para la vid y el vino. Las prensas neumáticas y los tanques de acero inoxidable dejaron atrás los sistemas anteriores. A partir de entonces se hizo posible obtener el mosto en forma más suave, sin romper la pepita, a la vez que la fermentación se realizaba a temperaturas más controladas y homogéneas. Se volvió a ofrecer un trato cuidadoso al mosto, recuperando, mutatis mutandis, muchas actitudes del período tradicional de la historia vitivinícola chilena.

\section{REFERENCIAS}

Artola Beuzón, Francisco. 2005. Entre vinos, toneles y botellas. Puerto de Santa María: Ediciones Ayuntamiento de Santa María.

Blasco Ibáñez, Vicente. 1989. La bodega [1ª ed.: 1905]. Sevilla: Biblioteca de la Cultura Andaluza, Introducción de Isabel Román Gutiérrez.

Brochado de Almeida, Carlos; Paulo Costa Pinto y Pedro Miguel Brochado de Almeida. 1996. "Os lagares cavados na rocha do castelo de Castorigo - Pegarinhos (Alijó)”. Douro II (4), (2º): 15-24.

Brown, Kendall. 2001. "El desarrollo de la viticultura colonial en el sur del Perú: los vinos y aguardientes de Arequipa”. En: Maldonado Rosso, Javier (ed.). 
Actas del I Simposio de la Asociación Internacional de Historia y Civilización de la vid y el vino. Vol. I. Puerto de Santa María: Ayuntamiento de El Puerto de Santa María, 471-480.

Canu, G. 1931. "El uso de los lagares en la vendimia”. Boletín de la Sociedad Nacional de Agricultura, Santiago, LXIII, 3 (marzo): 163-164.

Castro, Luis. 2009. Modernización y conflicto social: la expropiación de las aguas de regadio a los campesinos del valle de Quisma (oasis de Pica) y el abastecimiento fiscal a Iquique, 1880-1937. Valparaíso: Universidad de Valparaíso.

Celestino Pérez, Sebastián (editor). 1995. Arqueología del vino. Los orígenes del vino en Occidente. Jerez de la Frontera: Consejo Regulador de Jerez, Manzanilla y Sanlúcar de Barrameda.

Celestino Pérez, Sebastián (editor científico). 1996. El vino en la antigüedad romana. (Simposio arqueología del vino, Jerez, 2, 3 y 4 de octubre 1996). Madrid, Universidad Autónoma de Madrid.

Cerrillo Martín de Cáceres, Enrique. 1996. "La producción doméstica de vino en la Antigüedad Romana”. En: Celestino Pérez, Sebastián (ed. científico). El vino en la antigüedad romana (Simposio arqueología del vino, Jerez, 2, 3 y 4 de octubre 1996). Madrid: Universidad Autónoma de Madrid, 63-78.

Covarrubias Orozco, Sebastián. 1995. Tesoro de la lengua castellana o española, Madrid, s/e, 1611. Edición moderna consultada: Felipe Maldonado (editor), Manuel Camarero (revisor). Madrid: Castalia.

Del Pozo, José. 1999. Historia del vino chileno desde 1850 hasta hoy. 2a ed. Santiago: Universitaria.

Draghi Lucero, Juan. 1946. "La bodega mendocino-sanjuanina en la primera época colonial”. Revista de la Sociedad de Historia y Geografía de Cuyo II (Mendoza, 4 trimestre): 213-220. Edición reciente: en Draghi Lucero, Juan. Investigaciones Históricas, Mendoza: Zeta, 2005: 87-93.

Draghi Lucero, Juan. 1991. Andrés Tejeda. Miguel Amado Pouget. Mendoza: Ediciones Culturales de Mendoza.

Ferreira dos Santos, María José, Pedro Brochado de Almeida y Sandra Raquel Rodrígues. 2000. “Dos sepulcros e lagares de Rabacal (Meda)”. Douro 9: 179206.

Gay, Claudio. 1973. Historia física y política de Chile. Tomo II: Agricultura. [1 ${ }^{\mathrm{a}}$ ed.: París, s/e, 1855]. Santiago: ICIRA.

Gómez Bellard, Carlos y Pierre Guerin. 1995. "Los lagares de Atl de Benimaquia (Denia): en los inicios del vino ibérico”. En: Celestino Pérez, Sebastián (ed.). Arqueología del vino. Los orígenes del vino en Occidente. Jerez de la Frontera: Consejo Regulador de Jerez, Manzanilla y Sanlúcar de Barrameda: 241-270.

Guyot, Jules. 1861. Culture de la vigne et vinification. $2^{\mathrm{a}}$ ed., Paris, s/e.

Guyot, Jules. 1868. Étude des vignobles de France pour servir à l'enseignement mutuel de la viticultura et de la vinification francaises. Paris: Imprimerie Impériale (3 tomes).

Huerta, Lorenzo. 2004. "Historia de la producción de vinos y piscos en el Perú”. Universum 19: 44-61. 
Iglesia Berzosa, Javier. 2001. "Arquitectura tradicional vitivinícola de la Rivera del Duero burgalesa". En: Maldonado Rosso, Javier (editor). Actas del I Simposio de la Asociación Internacional de Historia y civilización de la vid y el vino. Vol. I. Puerto de Santa María: Ayuntamiento del Puerto de Santa María, 347-355.

Laranjeira Brochado, Claudio. 2001. "A lagareta de contrapeso da Quinta do Forte - Moncâo". Douro 12: 63-80.

Laranjeira Brochado, Claudio. 2004. "A arqueología de oito lagares cavados na rocha de entre Lima e Cávado". Douro 18: 13-31.

Lesko, L.H. 1978. King Tut's Wine Cellar. Berkeley: s/e.

López, Celia. 2005. Con la cruz y con el dinero. Los jesuitas del San Juan colonial. San Juan: Editorial de la Universidad de San Juan.

Maldonado Rosso, Javier (editor). 2001. Actas del I Simposio de la Asociación Internacional de Historia y civilización de la vid y el vino. 2 vols. Puerto de Santa María: Ayuntamiento del Puerto de Santa María.

Meeks, D. 1993. "Oleiculture et viticultura dans l'Egypte pharaonique". En: Amouretti, M.C. and Brun, J.P. (eds.). La production du vin et de l'huile en Méditerranée. BCH Supplément XXVI, 3-38.

Muñoz, Juan Guillermo. 2001. "Las viñas y el vino en Colchagua en el siglo XVII". En: Boletín de la Academia Chilena de la Historia (Santiago), 165-204.

Noya Gallardo, Carmen. 1993. La terminología vinícola jerezana en inglés. Mecanismos lingüísticos y estudios de léxico. Cádiz: Universidad de Cádiz.

Piqueras, Juan. 1986. Historia y guía de los vinos valencianos. Valencia: Generalitat Valenciana.

RAE (Real Academia Española). 2002. Diccionario de autoridades. Madrid, 1726, 3 tomos. Edición facsimilar: Madrid: Gredos.

Rice, Prudence and Greg Smith. 1989. “The Spanish Colonial Wineries of Moquegua, Peru”. Historical Archaeology 23: 41-49.

Rice, Prudence. 1996. "Peru's colonial wine industry and its European background”. Antiquity 70, 270 (december): 785-800.

Rivera Medina, Ana María. 2007a. Vitivinicultura y patrimonio en los Vásquez del Carril (1731-1815) San Juan, Argentina. San Juan: Editorial Fundación de la Universidad de San Juan.

Rivera Medina, Ana María. 2007b. "La infraestructura para la elaboración de caldos. Bodegas y lagares en San Juan de la Frontera (s. XVII-XVIII)". Universum 22, 1: 136-150.

Rodrígues Cosme, Susana. 2001. "O lagar romano de Aldeia Nova/Olival dos Telhôes (Almendra, Vila Nova de Foz Côa)". Douro 12: 55-62.

Rojas, Manuel. 1891. Tratado de viticultura y vinificación. Talca: Imprenta de la Libertad.

Ruiz Mata, Diego. 1995. "El vino en la época prerromana en Andalucía occidental". En: Celestino Pérez, Sebastián (ed.). Arqueología del vino. Los orígenes del vino en Occidente. Jerez de la Frontera: Consejo Regulador de Jerez, Manzanilla y Sanlúcar de Barrameda: 156-212. 
Salcedo Garcés, Fabiola. 1995. "La iconografía del vino en el mundo romano". En: Celestino Pérez, Sebastián (ed.). Arqueología del vino. Los orígenes del vino en Occidente. Jerez de la Frontera: Consejo Regulador de Jerez, Manzanilla y Sanlúcar de Barrameda: 97-116.

Sánchez Andaur, Raúl. 2006. "Viticultores jesuitas en el Obispado de Concepción (Chile)”. Universum 21, 1: 92-103.

Siméon, Rémi. 2004. Diccionario de la lengua náhuatl o mexicana. $17^{a}$ ed. México: Siglo XXI.

Soldi, Ana María. 2006. "La vid y el vino en la costa central del Perú, siglos XVI y XVII". Universum 21, 2: 42-61.

Unwin, Tim. 2001. El vino y la viña; geografía histórica de la viticultura y el comercio del vino. Barcelona: Tusquets.

Viana Antunes, Joao y Baère de Faria, Pedro. 2002. "Lagares do Alto Douro Sul. Tipologias e tecnologia”. Douro 14: 65-80. 